\title{
Thermodynamic properties of mixed-layer illite-smectite by calorimetric methods: Acquisition of the enthalpies of mixing of illite and smectite layers
}

H. Gailhanou ${ }^{a}$, P. Blanc ${ }^{a}$, J. Rogez ${ }^{b}$, G. Mikaelian ${ }^{b}$, H. Kawaji', J. Olives ${ }^{d}$, V. Montouillout ${ }^{e}$, J.-M. Grenèchef,

P. Vieillard ${ }^{g}$, E.C. Gaucher ${ }^{a, 1}$, C.I. Fialips ${ }^{\mathrm{h}, 1}$, B. Madéh

${ }^{a} B R G M, 3$ av. C. Guillemin, BP 36009, 45060 Orléans Cedex 2, France

' IM2NP, F.S.T. Saint-Jérôme, Case 251, Aix Marseille Université, 13397 Marseille Cedex 20, France

${ }^{\mathrm{c}}$ Tokyo Institute of Technology, 4259 Nagatsuta-cho, Midori-ku, Yokohama, 226-8503 Japan

${ }^{d}$ CINaM-CNRS, Aix-Marseille Université, Campus de Luminy, Case 913, 13288 Marseille Cedex 9, France

${ }^{\text {e}}$ CEMHTI-CNRS-UPR-3079, 1D av. de la Recherche Scientifique, 45071 Orléans, France

'IMMM-UMR-CNRS-6283, Le Mans Université, 72085 Le Mans cedex, France

${ }^{9}$ CNRS-IC2MP-UMR-7285 Hydrasa, 5 av. Albert Turpain, 86073 Poitiers Cedex, France

${ }^{\mathrm{h}}$ Andra, Research \& Development Division, Transfer Department, 92298 Châtenay-Malabry, France

${ }^{1}$ Present address: TOTAL, CSTJF, Avenue Larribau, 64018 Pau Cedex 


\section{ABSTRACT}

The stability of illite-smectite interstratified with respect to discrete illite and smectite minerals was investigated by measuring their thermodynamic properties. The standard thermodynamic properties of the illite-smectite ISCz-1 mineral ( $G, H, S, C_{p}$, and $V$ ) were determined between $298.15 \mathrm{~K}$ and $375 \mathrm{~K}$ by using calorimetric methods. Moreover, the enthalpies of mixing between the illite and smectite layers were measured at $298.15 \mathrm{~K}$ by acid solution calorimetry from a complete series of illite-smectite interstratified minerals (Shinzan area, Japan). The measured values were slightly negative, with a minimum value of -3.7 $\mathrm{kJ} \mathrm{mol}^{-1}$. This contributed to the stability of the mixed-layer with respect to a mechanical mixture of illite and smectite. In addition, the model from Blanc et al. (2015) was implemented to estimate the thermodynamic properties of the interstratified illite-smectite ISCz-1 mineral. The predicted values were consistent with the experimental ones. However, the estimates were slightly improved by considering the thermodynamic properties of the mixture of the illite and smectite components and then adding the terms of energies of mixing. This could be confirmed by establishing the stability domains of ISCz-1 and those of the corresponding illite and smectite end-members according to Meunier and Velde's determination of the smectite to illite reaction pathways (Meunier and Velde, 1989).

Key words: illite-smectite, enthalpies, heat capacities, entropies, Gibbs free energies, calorimetry. 


\section{Introduction}

Illite/smectite mixed layer clay minerals (I/S) are widely present in the natural environment and occur in various contexts, notably during diagenetic processes in sedimentary basins ([3,4], among others) or resulting from the hydrothermal alteration of volcanic or plutonic rocks ([5-7], among others). Understanding the processes associated with the transformation of smectite into illite/smectite and their consequences on the mechanical and geochemical behaviors of clayey formations is of great importance in some major application fields, such as oil exploration or nuclear waste disposal. For instance, this transformation modifies the porosities of oil and gas reservoirs and consequently the oil reserves. It was and is still widely used as a geothermometer for the early diagenesis stage (possibly combined with other tools such as the $\mathrm{Na} / \mathrm{K}$ or $\mathrm{Si}$ geothermometer or stable isotope analyses) in order to assess the maturity, in terms of the P-T-X reaction pathway, of a given reservoir [8]. In addition, the smectite-to-illite conversion may generate overpressures in sedimentary basins due to the dehydration of smectite and the precipitation of secondary minerals [9-11] that can be problematic for the functioning of oil wells. Furthermore, according to Gaucher and Blanc's review [12], the transformation of smectite to illite-smectite and then illite could be possibly expected at cement/clay interfaces after long periods of reaction times within the framework of deep disposal. Alkaline disturbance will generate mineralogical transformations at the cement/clay interface, in particular that of bentonite, thus implying a decrease of the smectite content. The latter will affect the swelling properties and the retention capacities of the clayey barrier near the cement/clay interface. Such reactions have to be integrated in the geochemical calculations used for performance assessments.

The thermodynamic stability of illite/smectite remains an unsolved issue. Numerous studies based on the mineralogical characterization of clays in natural systems ([13-18], among others) and in laboratory experiments ([19-23], among others) were performed in order to better understand the reaction mechanisms of the smectite illitization during hydrothermal alteration and diagenetic processes. Several authors ([19] and references therein, [21-23]) showed the coexistence of several phases (smectite, illite and one or more intermediate illite/smectite phases) during the transformation of smectite to illite.

By collecting the chemical analyses of natural I/S samples, Meunier and Velde [2] described the interstratified minerals using a ternary solid-solution model with one illite and two montmorillonite end- 
members. Based on this approach, Blanc et al. [24] developed a thermodynamic model that allowed for the calculation of the energies of the mixing of illite and smectite layers depending on the degree of ordering of the stacking sequences. The resulting Gibbs free energies of mixing are then slightly negative, thus suggesting the stability of illite-smectite mixed-layers with respect to the mechanical mixture of the pure illite and smectite layers.

The present work focuses on the measurement of thermodynamic properties of I/S minerals with two main objectives.

- To acquire a complete set of thermodynamic properties $\left(G, H, S\right.$, and $\left.C_{p}\right)$ for an illite-smectite mineral (ISCz-1), based on calorimetric methods $([25,26])$, which could be used to supply the thermodynamic databases (e.g., ThermoChimie [27] and Thermoddem [28]) used for geochemical modeling calculations. Until now, the lack of thermodynamic data for illite/smectite mixed layers is a limitation to properly model the smectite-to-illite conversion.

- To acquire the enthalpies of the mixing of the illite-smectite layers for a series of interstratified illite-smectite (hydrothermal alteration minerals coming from the Shinzan Area; [7,29]).

In addition, the present work allows for the checking of the reliability of the predictive model from Blanc et al. [1] for the thermodynamic properties of interstratified illite-smectite. Based on the properties measured here, the influence of the thermodynamic parameters of mixing can be discussed, including the configurational entropy associated with the cationic disordering in crystallographic sites of clay minerals and the specific interactions between smectite and illite layers within the I/S stacking sequence.

\section{Materials and methods}

\subsection{Clay samples}

The ISCz-1 sample is a mixed-layer illite-smectite, originating from Slovakia. It was provided by the Source Clays Repository of the Clay Minerals Society (Chipera and Bish [30]).

After sieving the ISCz-1 sample to a size of $<20 \mu \mathrm{m}$, the $<2 \mu \mathrm{m}$ fraction was separated by centrifugation. This was then twice dispersed in $\mathrm{CaCl}_{2} 0.5 \mathrm{M}$ solution for $24 \mathrm{~h}$ and centrifuged. Therefore, the sample was washed with a $\mathrm{CaCl}_{2} 0.001 \mathrm{M}$ solution by using a dialysis bag for 3 days. In the present study, 
$\mathrm{Ca}^{2+}$ was preferred to $\mathrm{Na}^{+}$for the saturation of the smectitic interlayers in order to facilitate the washing of the clay sample by avoiding the osmotic swelling of smectite. Eventually, the sample was dried at $40^{\circ} \mathrm{C}$ and then $60^{\circ} \mathrm{C}$ for several days. In the following, the sample referred to as ISCz-1 represents this treated sample.

A series of fourteen illite-smectite mixed-layers samples coming from the Shinzan area in northeast Japan was also used for this study. This series, which is well described in the literature (Inoue et al. [7,29]), is noticeable since it consists of a complete mixed-layer series with chemical compositions that vary from montmorillonite to illite end-members. The series results from the hydrothermal alteration of dioctahedral micas/smectites. The continuous conversion of smectite into illite was described by Inoue et al. [29]. The main transformation mechanism suggested by the authors was based on the dissolution of smectite and the crystallization of illite. A solid-state transformation mechanism was also shown from high resolution transmission electron microscopy (HRTEM) observations ([31,32]).

\subsection{Analysis and characterization of the samples}

\subsubsection{ISCz-1 sample}

The chemical analyses of $\mathrm{Si}, \mathrm{Al}, \mathrm{Ti}, \mathrm{Fe}$ (total), $\mathrm{Mn}, \mathrm{Ca}, \mathrm{Mg}, \mathrm{K}, \mathrm{Na}$ and $\mathrm{P}$ were performed using X-ray fluorescence spectrometry. The results of these analyses are presented in Table 1 . The amounts of total carbon and total sulfur were determined by infrared spectroscopy after burning the samples at $900^{\circ} \mathrm{C}$ in an oxygen atmosphere. The amount of $\mathrm{Fe}^{2+}$ was determined by ${ }^{57} \mathrm{Fe}$ Mössbauer spectrometry, as described further in the text (Section 2.2.1).

The chemical composition of the ISCz-1 sample (Ca-saturated) differs slightly from that of the previous Na-saturated ISCz-1 sample that was used for the heat capacity measurements in Gailhanou et al. [33] (Table 1). Both samples were supplied by the Clay Minerals Society with several years of intervals. The following study of the thermodynamic properties of the present ISCz-1 sample is complementary to the previous work from Gailhanou et al. [33]. 
Table 1. Chemical analyses of the sample ISCz-1 $\left(<2 \mu \mathrm{m}\right.$ clay fraction). Mass fractions $w_{i}, \mathrm{XRF}=\mathrm{X}$-ray fluorescence spectrometry, ${ }^{57} \mathrm{Fe}$ Möss. $={ }^{57} \mathrm{Fe}$ Mössbauer spectrometry, IR $=$ infra-red spectroscopy.

\begin{tabular}{|c|c|c|c|}
\hline & $\begin{array}{c}\text { ISCz-1 } \\
\text { (this study) } \\
/ 10^{2} w_{i} \text { per wt.\% }\end{array}$ & $\begin{array}{c}\text { Na-sat. ISCz-1 } \\
\text { ([33]) } \\
110^{2} w_{i} \text { per wt.\% }\end{array}$ & Analytical technique \\
\hline $\mathrm{SiO}_{2}$ & $53.8^{a}$ & 52.6 & $\mathrm{XRF}$ \\
\hline $\mathrm{Al}_{2} \mathrm{O}_{3}$ & $24.4^{a}$ & 26.7 & XRF \\
\hline $\mathrm{CaO}$ & $1.1^{\mathrm{a}}$ & $<0.1$ & XRF \\
\hline $\mathrm{Fe}_{2} \mathrm{O}_{3}$ & $1.39^{\mathrm{a}}$ & 0.97 & XRF, ${ }^{57} \mathrm{Fe}$ Möss. \\
\hline $\mathrm{FeO}$ & $0.17^{a}$ & 0.30 & ${ }^{57} \mathrm{Fe}$ Möss. \\
\hline $\mathrm{K}_{2} \mathrm{O}$ & $5.07^{\mathrm{a}}$ & 5.96 & XRF \\
\hline $\mathrm{MgO}$ & $2.2^{a}$ & 2.1 & XRF \\
\hline $\mathrm{Na}_{2} \mathrm{O}$ & $<0.2$ & 1.0 & $\mathrm{XRF}$ \\
\hline $\mathrm{TiO}_{2}$ & $0.13^{a}$ & 0.09 & XRF \\
\hline $\mathrm{P}_{2} \mathrm{O}_{5}$ & $<0.05$ & 0.13 & XRF \\
\hline Loss on ignition & 11.9 & 10.0 & Weight loss (up to $1000^{\circ} \mathrm{C}$ ) \\
\hline C total & 0.07 & 0.04 & IR \\
\hline S total & $<0.01$ & 0.06 & IR \\
\hline Total & 100.25 & 99.95 & \\
\hline
\end{tabular}

The cationic exchange capacity (CEC) of the sample was measured after saturating the sample with a chloride cobalt hexammine solution according to the method described in Gaucher et al. [34]. The total CEC was measured by colorimetry, and the exchangeable cations $\left(\mathrm{Na}^{+}, \mathrm{Ca}^{2+}, \mathrm{K}^{+}, \mathrm{Mg}^{2+}\right)$ were analyzed by ionic chromatography. The results are provided in Table 2. The obtained CEC value is consistent with the one measured for the ISCz-1 sample at 39.0 meq. $100 \mathrm{~g}^{-1}$ [33].

Table 2. Equivalent fractions of exchangeable cations $E_{N a}, E_{C a}, E_{M g}, E_{K}$ in meq/100 g of dry sample and cationic exchange capacity calculated $C E C_{c a l c .}=E_{N a}+E_{C a}+E_{M g}+E_{K}$ and measured by colorimetry $C E C_{\text {meas. }}$ for the ISCz-1 sample (<2 $\mu$ m clay fraction) in meq per $100 \mathrm{~g}$ of dry sample.

\begin{tabular}{lcccccc}
\hline Sample & $E_{N a}$ & $E_{C a}$ & $E_{M g}$ & $E_{K}$ & $C E C_{\text {calc. }}$ & $C E C_{\text {meas. }}$ \\
\hline ISCz-1 & $0.4^{\mathrm{a}}$ & $39.7^{\mathrm{a}}$ & $<0.5$ & $3.8^{\mathrm{a}}$ & $43.9^{\mathrm{a}}$ & $44.1^{\mathrm{a}}$ \\
& & & & \\
\hline
\end{tabular}

Moreover, XRD analyses were conducted on the ISCz-1 sample on powders and on oriented deposits using the method described by Gailhanou et al. [33]. For the powdered samples, both the identification of the 
nature of impurities and their semi-quantification were performed using Modpattern [35] with an internal corundum standard (Fig. 1). In the present case, only rough estimates of the proportions of the impurities could be obtained by modeling due to the lack of a reference pattern for Ca-saturated illite-smectite.

Moreover, the modeling of the XRD pattern on the glycolated oriented deposit was performed by using the Arquant code [36], which allowed for the identification and quantification of a small amount of kaolinite. Finally, the amounts of impurities in the purified sample estimated by XRD modeling are $4.2,3.8$ and 0.45 wt.\% of quartz, K-feldspar and kaolinite, respectively. Moreover, as a result of the modeling of the XRD pattern on the glycolated deposit and in agreement with Chipera and Bish's results [30], the interstratified ISCz-1 was ordered with a degree of interstratification ordering $R=1$ (Reichweite index) and the illite layer content was estimated at $70 \%$.

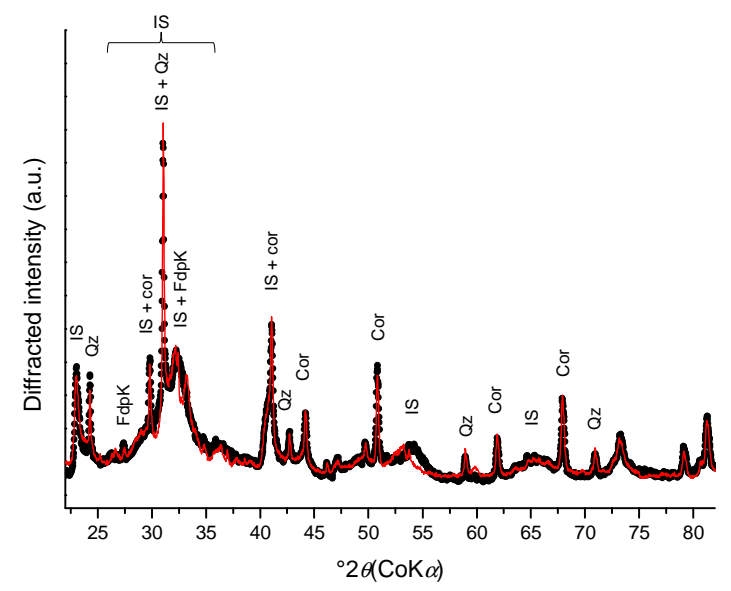

(a)

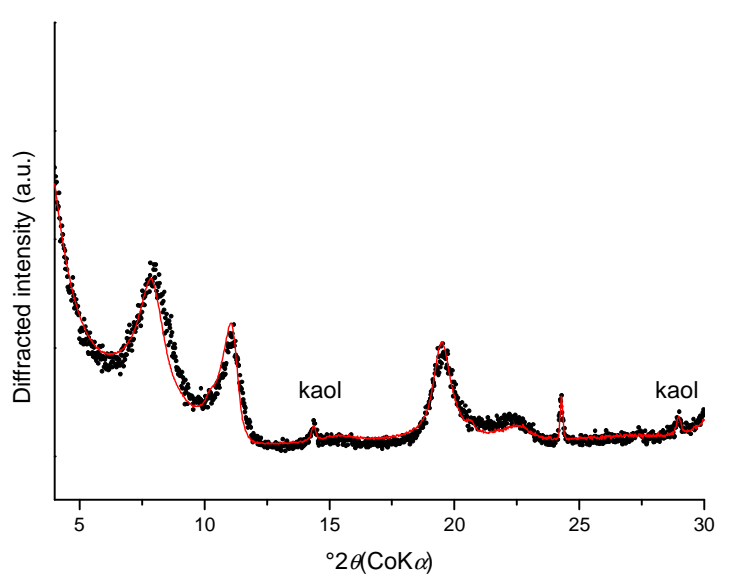

(b)

Fig. 1. Modeled XRD patterns obtained for the ISCz-1 sample $(<2 \mu \mathrm{m}$, Ca-saturated) on (a) the powdered sample and (b) the glycolated oriented deposit. IS = mixed-layer ISCz-1, Qz = quartz, Cor = corundum (internal standard of 9.19 wt.\%), FdpK = K-feldspar, and Kaol = Kaolinite (in black, experimental; in red, modeling).

In addition, some investigations were performed by using ${ }^{29} \mathrm{Si}$ and ${ }^{27} \mathrm{Al} \mathrm{NMR}$ in order to complete the characterization of the silicates and aluminosilicates impurities. A ${ }^{29} \mathrm{Si} N \mathrm{NR}$ spectrum was acquired with a 
Bruker Advance $300 \mathrm{MHz}\left(\mathrm{B}_{0}=7.0 \mathrm{~T}\right)$ spectrometer operating at a $79.5 \mathrm{MHz}$ frequency for ${ }^{29} \mathrm{Si}(\mathrm{Fig} .2 \mathrm{a})$. Notably, this analysis revealed, in addition to illite-smectite component (between -80 and $-100 \mathrm{ppm}$ ), the presence of quartz (-107.52 ppm) and the absence of other silica impurities (cristobalite or amorphous silica, notably). The amount of quartz was estimated to 5.4 wt.\% in the ISCz-1 sample. This result is in good agreement with the XRD estimate of 4.2 wt.\%.
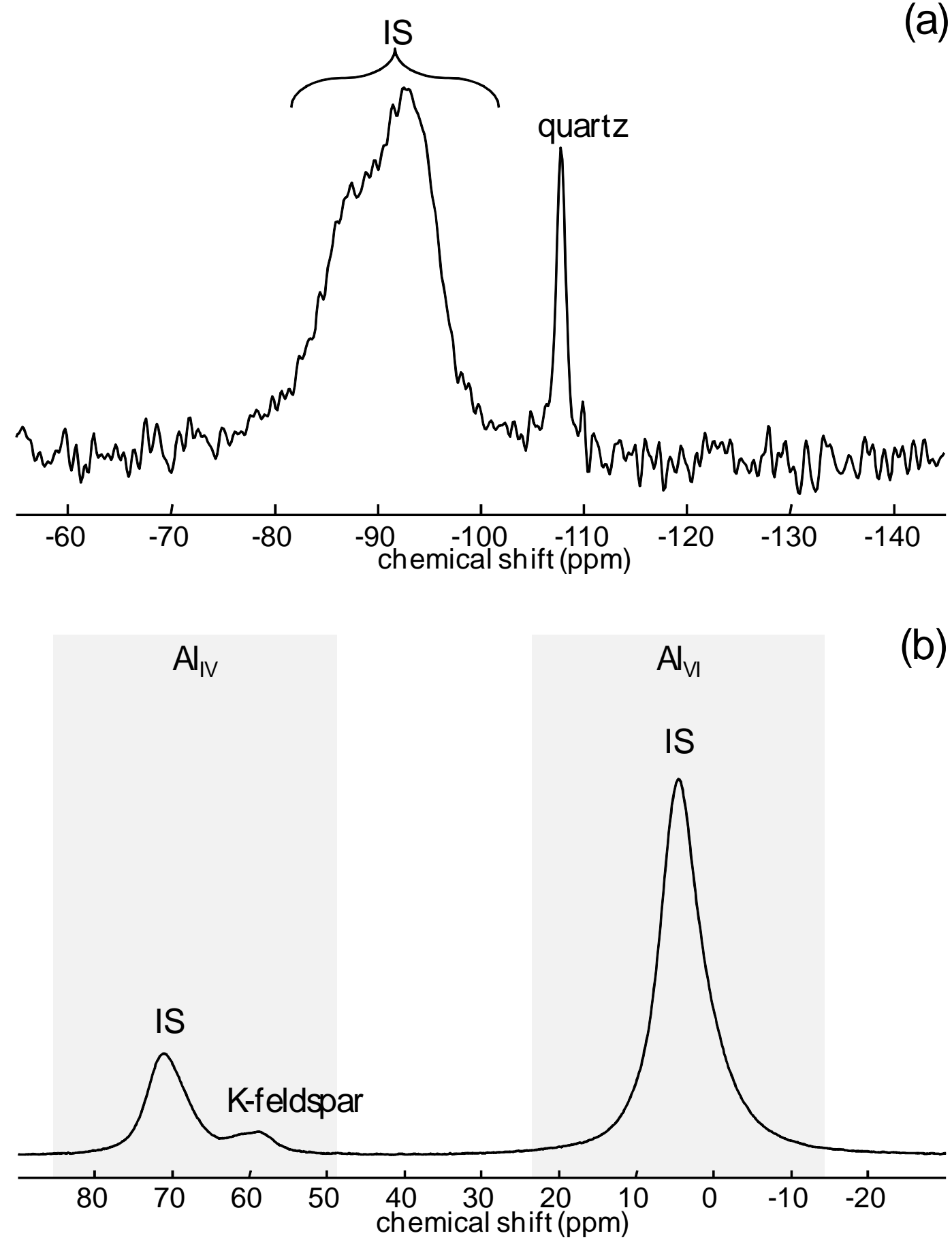
Fig. 2. Identification and quantification of impurities in the ISCz-1 sample $\left(<2 \mu \mathrm{m}\right.$ clay fraction) by NMR: (a) ${ }^{29} \mathrm{Si}$ and (b) ${ }^{27} \mathrm{Al}$ NMR spectra. Note: $1 \mathrm{ppm}=10^{-6}$.

For its part, the ${ }^{27} \mathrm{Al}$ NMR spectrum (Fig. 2b) acquired with a Bruker Advance $750 \mathrm{MHz}$ spectrometer $\left(\mathrm{B}_{0}=17.7 \mathrm{~T}, \mathrm{~V}_{\mathrm{RF}}\left({ }^{27} \mathrm{Al}\right)=195.5 \mathrm{MHz}\right)$ exhibits three main signals for one six-fold coordinated aluminum $\left(\delta_{\mathrm{CG}}=4.6 \mathrm{ppm}\right)$ and two four-fold coordinated aluminum $\left(\delta_{\mathrm{CG}}=59.4\right.$ and $\left.71.1 \mathrm{ppm}\right)$. Both $\delta_{\mathrm{CG}}=4.6$ and 71.1 ppm sites are commonly attributed to $\mathrm{Al}^{\mathrm{VI}}$ and $\mathrm{Al}^{\mathrm{IV}}$ in illite-smectite $[37,38]$, while the signal at $\delta_{\mathrm{CG}}=59.4 \mathrm{ppm}$ is compatible with $\mathrm{Al}^{\mathrm{IV}}$ in K-feldspar as detected by XRD (Cuadros and Linares [37]). The spectrum was modeled using the Dmfit software [39]. The component at $\delta_{\mathrm{CG}}=59.4 \mathrm{ppm}$ corresponds to 2.9 at $\%$ of the aluminum of the sample. The resulting proportion of K-feldspar impurities in the ISCz-1 sample was then estimated to be $3.8 \mathrm{wt} . \%$, which is in agreement with the value obtained by XRD modeling.

The proportions of ferric and ferrous ions in the clay minerals and, if present, amounts of ferrous or ferric impurities can be determined by ${ }^{57} \mathrm{Fe}$ Mössbauer spectrometry. These analyses were performed using a conventional constant acceleration Mössbauer spectrometer in transmission geometry that was equipped with a ${ }^{57} \mathrm{Co}(\mathrm{Rh})$ source. The isomer shift values were corrected based on the calibration of the velocity scale made from $\alpha-\mathrm{Fe}$ at $300 \mathrm{~K}$. The amount of $\mathrm{Fe}$ in the sample was approximately $5 \mathrm{mg} \mathrm{cm}^{-2}$. The spectra obtained at $300 \mathrm{~K}$ and $77 \mathrm{~K}$ were fitted using a discrete number of independent quadrupolar doublets and magnetic sextets composed of lorentzian lines, where the line width at half-height $\Gamma\left(\mathrm{mm} \mathrm{s}^{-1}\right)$, the isomer shift $\delta\left(\mathrm{mm} \mathrm{s}^{-1}\right)$ and the quadrupole splitting $\Delta \mathrm{E}_{\mathrm{Q}}\left(\mathrm{mm} \mathrm{s}^{-1}\right)$ were refined using a least-square fitting procedure.

The ${ }^{57} \mathrm{Fe}$ Mössbauer spectra for the ISCz-1 sample $(<2 \mu \mathrm{m})$ are displayed in Fig. 3 . The $300 \mathrm{~K}$ spectrum (inset Fig. 3) exhibits a quadrupolar broadened asymmetrical feature and a single line that can be described using two components that are clearly attributed to ferric and ferrous species. However, one can see that the baseline remains distorted (as confirmed by a spectrum obtained at $12 \mathrm{~mm} \mathrm{~s}^{-1}$, which is not shown here). This feature results from the presence of superparamagnetic Fe species, which is the presence of ultra-fine Fe-bearing grains. Consequently, the hyperfine structure was investigated at $77 \mathrm{~K}$ to get the blocked magnetic states of some Fe species, as confirmed in Fig. 3. The description unambiguously requires 
several magnetic sextets and quadrupolar doublets, but a single broadened line was added to better describe the baseline. The refined values of the Mössbauer parameters that were extracted from spectral modeling are listed in Table 3. The proportion of $\mathrm{Fe}$ in the clay mineral was estimated to be 42 at.\% of the total $\mathrm{Fe}$ content and the ratio $\mathrm{Fe}^{3+} /\left(\mathrm{Fe}^{2+}+\mathrm{Fe}^{3+}\right)$ was estimated to be $72 \%$. It is important to note the good agreement between the $\mathrm{Fe}^{2+}$ contents estimated at $300 \mathrm{~K}$ and $77 \mathrm{~K}$, assuming that the proportions are proportional to the relative absorption areas, i.e. assuming the same values of the Lamb-Mössbauer recoilless factors. The modeling allowed one to distinguish three magnetic phases, i.e., goethite $\left(\alpha-\mathrm{Fe}{ }^{3+} \mathrm{O}(\mathrm{OH})\right)$ as fine grains (magnetic sextets), ultra-fine superparamagnetic grains (single line) and likely bernalite (ideally $\mathrm{Fe}^{3+}(\mathrm{OH})_{3}$, [40]) or a bernalite/hematite mixture.

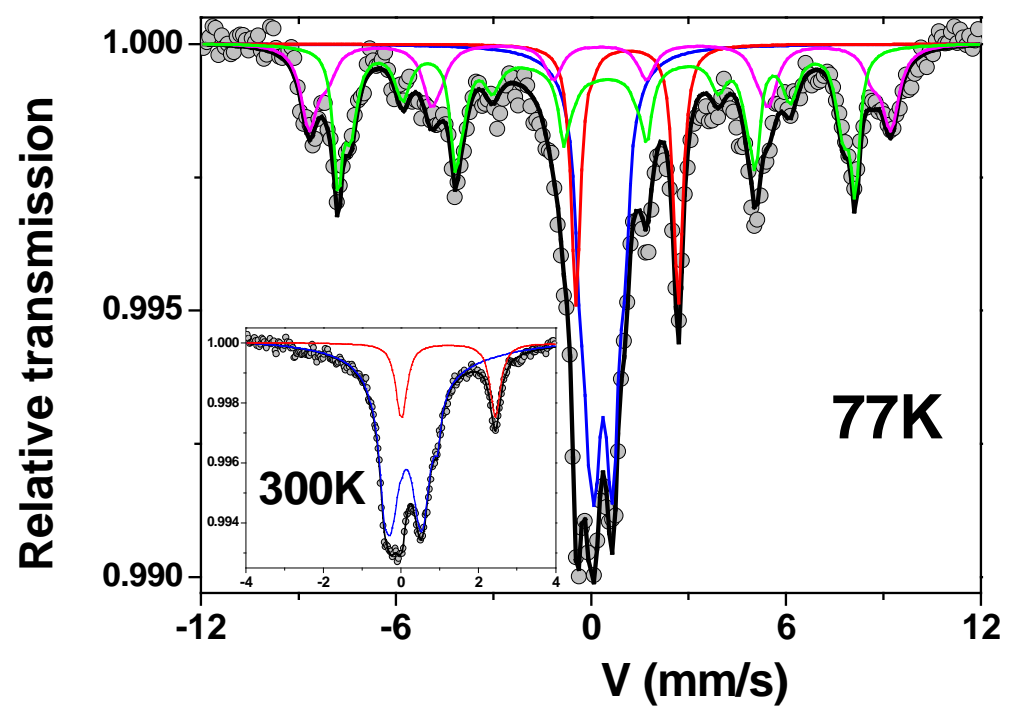

Fig. 3. ${ }^{57} \mathrm{Fe}$ Mössbauer spectra for the ISCz-1 sample $(<2 \mu \mathrm{m}$ clay fraction). The $77 \mathrm{~K}$ spectrum and its decomposition into 4 components: red for $\mathrm{Fe}^{2+}$ in clay, dark blue for $\mathrm{Fe}^{3+}$ in clay, green for the magnetic component of $\mathrm{Fe}^{3+}$ in goethite, and pink for the magnetic component of $\mathrm{Fe}^{3+}$ in bernalite. The inset represents the $300 \mathrm{~K}$ spectrum with the blue and red components attributed to ferric and ferrous species, respectively (see text). 
Table 3. ${ }^{57} \mathrm{Fe}$ Mössbauer parameters at $77 \mathrm{~K}$ for the ISCz-1 sample $(<2 \mu \mathrm{m}$ clay fraction): isomer shift value relative to that of the $\alpha-\mathrm{Fe}$ at $300 \mathrm{~K}$ I.S. $\left(\mathrm{mm} \mathrm{s}^{-1}\right)$, quadrupolar shift $2 \varepsilon$ or quadrupolar splitting $\Delta E_{Q}\left(\mathrm{~mm} \mathrm{~s}^{-1}\right)$, magnetic field $B_{h f}(T)$ and mole fraction of Fe for each component $X_{c}$.

\begin{tabular}{|c|c|c|c|c|c|}
\hline Mineral & $I . S^{a}$ & $2 \varepsilon^{a}$ or $\Delta E_{Q}^{a}$ & $B_{h f}{ }^{a}$ & $10^{2} X_{c}^{a}$ & Attributions \\
\hline \multirow[t]{2}{*}{ Illite-smectite } & 0.47 & 0.57 & & 27 & $\begin{array}{l}\mathrm{Fe}^{3+} \text { associated with clay minerals (structural } \\
\text { and/or sorbed ions) }\end{array}$ \\
\hline & 0.42 & 1.32 & & 4 & $\mathrm{Fe}^{3+}$ associated with clay minerals \\
\hline Illite-smectite & 1.30 & 3.06 & & 12 & $\mathrm{Fe}^{2+}$ associated with clay minerals \\
\hline Goethite & $\begin{array}{l}0.46 \\
0.47 \\
0.47\end{array}$ & $\begin{array}{l}-0.27 \\
-0.27 \\
-0.27\end{array}$ & $\begin{array}{l}49.2 \\
46.7 \\
36.8\end{array}$ & 28 & $\mathrm{Fe}^{3+}$ in goethite \\
\hline Bernalite & $\begin{array}{l}0.40 \\
0.40\end{array}$ & $\begin{array}{l}0.00 \\
0.00\end{array}$ & $\begin{array}{l}51.8 \\
55.3\end{array}$ & 17 & $\mathrm{Fe}^{3+}$ in bernalite \\
\hline $\begin{array}{c}\text { Goethite } \\
\text { (ultra-fine grains) }\end{array}$ & 0.46 & 0.00 & & 12 & $\mathrm{Fe}^{3+}$ in goethite \\
\hline
\end{tabular}

Thus, based on these results and considering the total amount of $\mathrm{Fe}_{2} \mathrm{O}_{3}$ in the sample (Table 1), the amounts of goethite and bernalite were estimated to $0.70 \mathrm{wt} . \%$ and $0.36 \mathrm{wt} . \%$, respectively.

From the preceding results, the final amounts of impurities were calculated and are reported in Table 4. The mean structural formula of illite-smectite was eventually calculated (Table 4) by subtracting the contributions of impurities that were obtained at ambient R.H. to the global chemical analyses from Table 1.

Table 4. Mass fractions of impurities in the ISCz-1 sample at ambient relative humidity (R.H.) $w_{i, r}$ and in dry sample $w_{i, d r y}$, mean structural formula and molar mass of illite-smectite $M$.

\begin{tabular}{|c|c|c|c|}
\hline Impurity & $\begin{array}{l}\text { Mass fraction at ambient R.H. } \\
\qquad 10^{2} w_{i, r}\end{array}$ & $\begin{array}{l}\text { Mass fraction in dry sample } \\
\qquad 10^{2} w_{i, d r y}\end{array}$ & $\begin{array}{l}\text { Analysis } \\
\text { method }\end{array}$ \\
\hline Quartz & 5.40 & 5.85 & ${ }^{29} \mathrm{Si} N M R$ \\
\hline goethite & 0.70 & 0.76 & ${ }^{57}$ Fe Mössbauer \\
\hline bernalite & 0.36 & 0.39 & ${ }^{57} \mathrm{Fe}$ Mössbauer \\
\hline Sample & \multicolumn{2}{|c|}{ Mean structural formula } & $\mathrm{M} / \mathrm{g} \mathrm{mol}^{-1}$ \\
\hline $\begin{array}{l}\text { ISCz-1 } \\
\text { (Gailhanou, 2007) }\end{array}$ & \multicolumn{2}{|c|}{$\left(\mathrm{Na}_{0.134} \mathrm{~K}_{0.530}\right)\left(\mathrm{Si}_{3.565} \mathrm{Al}_{0.435}\right)\left(\mathrm{Al}_{1.717} \mathrm{Mg}_{0.218} \mathrm{Fe}^{3+}{ }_{0.050} \mathrm{Fe}^{2+}{ }_{0.017}\right) \mathrm{O}_{10}(\mathrm{OH})_{2}$} & 385.04 \\
\hline
\end{tabular}


Finally, the mineralogical and chemical compositions of the present ISCz-1 sample were compared to those obtained for the previous Na-saturated ISCz-1 sample, which had been used for heat capacity measurements in Gailhanou et al. [33]. The amounts of impurities are significantly higher in the present ISCz1 sample than in the previous one, which contained approximately 0.75 wt.\% quartz and 1.5 wt.\% kaolinite. Moreover, the mean structural formula of the Ca-saturated ISCz-1 sample (this study) exhibits a slightly lower total layer charge $\left(0.62\right.$ eq. $\left./ \mathrm{O}_{10}(\mathrm{OH})_{2}\right)$ compared with the one previously obtained for the Na-saturated ISCz-1 sample at 0.66 eq. $/ \mathrm{O}_{10}(\mathrm{OH})_{2}$. The decrease of the layer charge is probably correlated to the increase of the total CEC, which were 0.44 and 0.39 eq. $\mathrm{kg}^{-1}$ for the present Ca-saturated ISCz-1 sample and the previous Na-saturated ISCz-1 sample, respectively. Both indicated amounts of smectite layers slightly higher in the present case than for the previously sample analyzed.

\subsubsection{Illite-smectite series from the Shinzan Area}

The illite/smectite samples cover the entire range of compositions from $0 \%$ to $100 \%$ smectite (Table 5) as determined by the X-ray diffraction analyses of ethylene-glycol solvated samples (Inoue et al. [29]). According to these authors, samples containing more than $50 \%$ smectite layers were randomly interstratified

(Reichweite index $g=0$ ), while the degrees of interstratification ordering increased progressively to $g=1$, $g=2$ and $g \geq 3$ with increasing illite contents.

The chemical compositions of all studied samples were determined by atomic absorption spectroscopy [41]. The mean structural formulae for the illite/smectite samples are given in Table 6 . 
Table 5. Illite/smectite interstratified minerals from the Shinzan hydrothermal alteration area in Japan. Drill holes, depth (m), proportions of smectite layers respectively to the total number of layers, illite $N_{i l}$ and smectite $N_{s m}$, and $g=$ Reichweite index, according to [29].

\begin{tabular}{lcccc}
\hline Sample & Drill Hole & Depth $z / m$ & $10^{2} N_{s m} /\left(N_{s m}+N_{i i}\right)$ & $g$ \\
\hline A (smectite) & Ws-2 & 183,5 & 100 & 0 \\
B & Ws-4 & 329,5 & 85 & 0 \\
C & Ws-4 & 383,0 & 73 & 0 \\
D & Ws-2 & 377,8 & 70 & 0 \\
E & Ws-2 & 407,4 & 68 & 0 \\
F & Ws-4 & 392,8 & 50 & 0 \\
G & Ws-2 & 423,2 & 40 & 1 \\
H & Ws-10 & 199,9 & 35 & 1 \\
I & Ws-4 & 440,6 & 30 & 1 \\
J & Ws-5 & 240,1 & 20 & 2 \\
K & Ws-7 & 123,6 & 15 & $\geq 3$ \\
L & Ws-7 & 115,5 & 15 & $\geq 3$ \\
M & Ws-7 & 197,0 & 5 & $\geq 3$ \\
N (illite) & Ws-8 & 420,9 & 0 & \\
\hline
\end{tabular}

Table 6. Mean structural formulae of the illite/smectite mixed-layers from the Shinzan area on the basis of 12 oxygen atoms, calculated from the chemical analyses in [41]. $\mathrm{Fe}^{3+}$ and Ti were assumed to be in octahedral sheets.

\begin{tabular}{ccccccccccccccc}
\hline & $\mathrm{A}$ & $\mathrm{B}$ & $\mathrm{C}$ & $\mathrm{D}$ & $\mathrm{E}$ & $\mathrm{F}$ & $\mathrm{G}$ & $\mathrm{H}$ & $\mathrm{I}$ & $\mathrm{J}$ & $\mathrm{K}$ & $\mathrm{L}$ & $\mathrm{M}$ & $\mathrm{N}$ \\
\hline $\mathrm{Si}$ & 3.886 & 3.822 & 3.786 & 3.714 & 3.692 & 3.728 & 3.586 & 3.524 & 3.560 & 3.483 & 3.542 & 3.473 & 3.397 & 3.329 \\
$\mathrm{Al}$ & 1.685 & 1.658 & 1.722 & 1.847 & 1.908 & 1.738 & 2.079 & 2.059 & 2.036 & 2.268 & 2.101 & 2.214 & 2.316 & 2.401 \\
$\mathrm{Fe}^{3+}$ & 0.124 & 0.116 & 0.096 & 0.086 & 0.069 & 0.130 & 0.078 & 0.070 & 0.096 & 0.033 & 0.017 & 0.029 & 0.033 & 0.065 \\
$\mathrm{Fe}^{2+}$ & 0.020 & 0.035 & 0.025 & 0.025 & 0.042 & 0.037 & 0.019 & 0.038 & 0.028 & 0.040 & 0.017 & 0.023 & 0.029 & 0.055 \\
$\mathrm{Mg}$ & 0.314 & 0.397 & 0.390 & 0.340 & 0.304 & 0.388 & 0.258 & 0.314 & 0.301 & 0.190 & 0.332 & 0.264 & 0.231 & 0.171 \\
$\mathrm{Ti}$ & 0.012 & 0.006 & 0.009 & 0.020 & 0.011 & 0.005 & 0.003 & 0.045 & 0.009 & 0.008 & 0.015 & 0.018 & 0.003 & 0.005 \\
$\mathrm{Mn}$ & 0.000 & 0.000 & 0.000 & 0.000 & 0.000 & 0.001 & 0.000 & 0.000 & 0.000 & 0.001 & 0.002 & 0.003 & 0.007 & 0.001 \\
$\mathrm{Ca}$ & 0.072 & 0.063 & 0.049 & 0.022 & 0.025 & 0.038 & 0.029 & 0.027 & 0.026 & 0.023 & 0.013 & 0.009 & 0.022 & 0.001 \\
$\mathrm{Na}$ & 0.162 & 0.223 & 0.211 & 0.258 & 0.226 & 0.152 & 0.208 & 0.101 & 0.103 & 0.004 & 0.004 & 0.004 & 0.005 & 0.011 \\
$\mathrm{~K}$ & 0.008 & 0.148 & 0.222 & 0.235 & 0.292 & 0.388 & 0.353 & 0.481 & 0.516 & 0.621 & 0.686 & 0.702 & 0.769 & 0.802 \\
\hline
\end{tabular}

A statistical analysis of the chemical compositions of the I/S minerals was performed using the Principal Component Analysis method $\left(\mathrm{XLSTAT}^{\odot}\right)$. The main trend of chemical dispersion is described by the eigenvector $\mathbf{F}_{1}$ and corresponds to the substitution $\mathrm{Si} \rightarrow \mathrm{KAl}$ that occurs during the transformation of montmorillonite to illite (Fig. 4). A second, less important trend seems to emerge along the $\boldsymbol{F}_{2}$ axis. Regarding the composition of the eigenvector $\mathbf{F}_{2}$, it represents the chemical dispersions for the elements $\mathrm{Si}, \mathrm{Mg}$ and $\mathrm{Al}$ and shows a correlation between $\mathrm{Si}$ and $\mathrm{Mg}$, whereas these latter ones are anti-correlated with Al. Thus, the dispersion of compositions along the $\mathbf{F}_{2}$ axis is probably associated with the Tschermak substitution $\mathrm{Al}^{\mathrm{IV}} \mathrm{Al}^{\mathrm{VI}}$ $\rightarrow \mathrm{Si}^{\mathrm{IV}} \mathrm{Mg}$, which corresponds to muscovite $\rightarrow$ celadonite. Finally, the main chemical dispersion occurs along 
the montmorillonite $\mathrm{A}$ - illite $\mathrm{N}$ axis, as expected. Nevertheless, because some compositions deviate from this axis, it is also necessary to take into account a supplementary dimension, along the $\mathbf{F}_{2}$ axis in order to describe all the compositions of the I/S minerals. In the following section, we propose to describe the compositions of these illite-smectite series using a ternary solid-solution that is composed of illite $\mathrm{N}$, montmorillonite $A$ and interstratified $F$ end-members. The interstratified $F$ end-member was selected since it exhibits the stronger celadonite-type component along $\mathbf{F}_{\mathbf{2}}$ (Fig. 4).

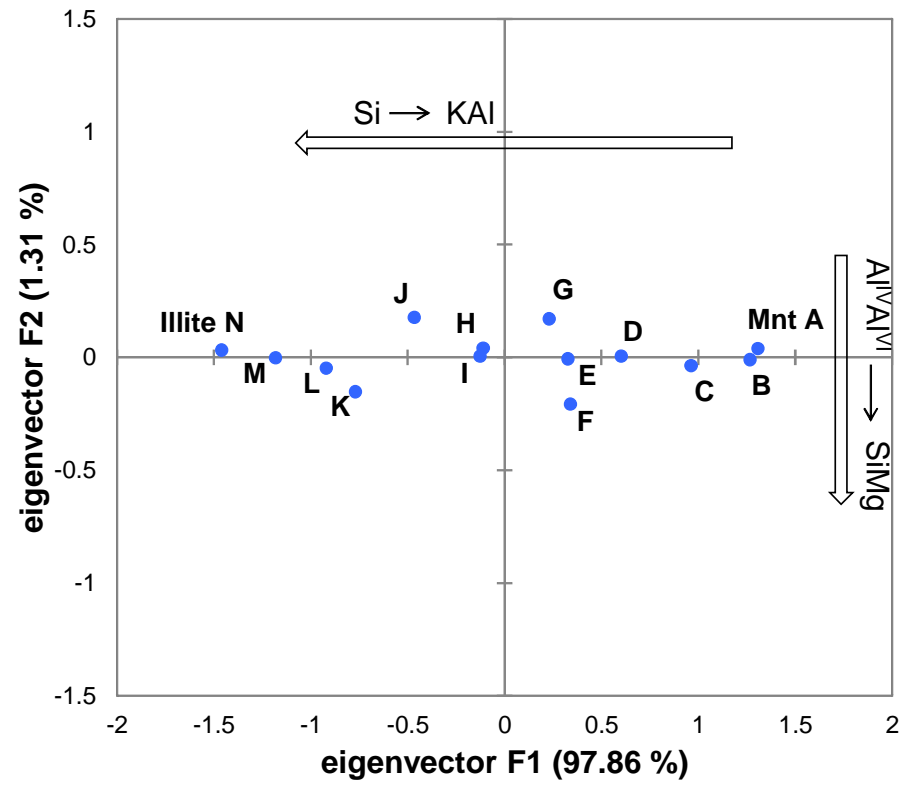

Fig. 4. Statistical treatment by PCA of the 14 compositions of I/S from the Shinzan area. The chemical trends shown by arrows were depicted from the components of the main eigenvectors $\mathbf{F}_{1}$ and $\mathbf{F}_{2}$. Mnt $A=$ Montmorillonite $A$.

\subsubsection{Hydration state of samples for calorimetric measurements}

Calorimetric measurements were performed on the dehydrated ISCz-1 sample. The dehydrated state was obtained by heating the sample at $150^{\circ} \mathrm{C}$ for $20 \mathrm{~h}$. The sample was then stored in a glove box under a dry Ar atmosphere $\left(\mathrm{H}_{2} \mathrm{O}<4 \mathrm{ppm}\right)$.

For the interstratified samples from the Shinzan hydrothermal area, the enthalpies of dissolution were acquired by Perbost et al. [41]. The samples were stored at room relative humidity before measurements. Their hydration states were not determined. Nevertheless, slight variations in relative humidities and therefore in the amounts of water adsorbed for a given sample were not expected to significantly affect the 
enthalpy of the dissolution of the sample because the contribution of the enthalpy of dilution is negligible compared to the total measured enthalpy of the dissolution and its associated uncertainty.

\subsection{Calorimetric methods}

\subsubsection{Heat capacity measurements}

For the dehydrated ISCz-1 sample, the heat capacities were measured by heat-pulse calorimetry between 2 and $330 \mathrm{~K}$ using a commercial apparatus (PPMS model 6000, Quantum Design Inc.; [42]). Measurements were performed twice in the temperature range by cooling the sample from $50 \mathrm{~K}$ to $2 \mathrm{~K}$ and heating it from $50 \mathrm{~K}$ to $330 \mathrm{~K}$, respectively. They were conducted on two pressed pellets weighing 4.16 and $14.93 \mathrm{mg}$, respectively, in order to check the reproducibility of the measurements. The relative uncertainties of the standard molar heat capacities $C_{p, m}^{\circ}$ were estimated to be $\pm 0.05 C_{p, m}^{\circ}$ for $2 \mathrm{~K}<T<50 \mathrm{~K}$ and $\pm 0.02 C_{p, m}^{\circ}$ for $\mathrm{T}>50 \mathrm{~K}$ according to the results from Dachs and Benisek [43] that were obtained for several standard reference powder samples that were encapsulated in Al-pans.

Moreover, the heat capacities of the dehydrated Ca-saturated ISCz-1 sample were also measured by using differential scanning calorimetry (DSC), between 300 and $520 \mathrm{~K}$. The apparatus was a Calvet DSC111 from Setaram. DSC calibration consisted in a commonly used procedure for temperature and enthalpy calibration and heat capacity calibration. Standard elements indium (Goodfellow, purity 99.999\%), zinc (Goodfellow, purity 99.999\%) and aluminium (Goodfellow, purity 99.999\%) were used for temperature and enthalpy calibration [44], and synthetic sapphire (National Bureau of Standards, [45]) for the heat capacity calibration, in the same conditions of nitrogen flow rate and heating rate as for the heat capacity measurements on the clay sample. The amount of each dehydrated sample was $140.03 \mathrm{mg}$. The heat capacity measurements were performed at $2 \mathrm{~K} \mathrm{~min}^{-1}$ heating rate, with temperature increase steps of $2.5 \mathrm{~K}$ and followed by temperature stabilization periods of $600 \mathrm{~s}$ allowing the heat flow to recover the baseline value.

The validation of the experimental data relies on the use of two heat capacity measurement techniques with a temperature overlapping domain, performed in two different laboratories (Tokyo Institute of Technology and IM2NP for PPMS and DSC measurements, respectively). Moreover, the measured data are 
compared with previously measured on a dehydrated ISCz-1 sample saturated by sodium [33], using both low-temperature adiabatic calorimetry between $10 \mathrm{~K}$ and $380 \mathrm{~K}$, and DSC between $300 \mathrm{~K}$ and $520 \mathrm{~K}$. Such verification procedure was already used successfully in previous studies for the same type of minerals $([25,26,33])$.

\subsubsection{Acid solution calorimetry at $298.15 \mathrm{~K}$}

The enthalpies of the dissolution of the dehydrated ISCz-1 sample and of the fourteen illite/smectite samples from the Shinzan area were measured by isothermal dissolution calorimetry at $298.15 \mathrm{~K}$ in $\mathrm{HF}$ $\mathrm{HNO}_{3}$ solutions. The apparatus was a highly sensitive Tian-Calvet calorimeter, i.e., the Calsol calorimeter [46]. The calorimeter was calibrated by dissolving THAM (tris(hydroxymethyl)aminomethane) crystal in a solution of hydrochloric acid at a molality of $0.12 \mathrm{~mol} \mathrm{kgw}^{-1}(\mathrm{kgw}=$ kilogram of water) under the same conditions as those used in the experiments of Ganteaume et al. [46]. The experimental procedure for the measurements was described in detail in Gailhanou et al. [25]. All the acids and THAM reagent used for calibration of the apparatus and the calorimetric measurements are analytical grade reagents, described in Table 7. The acid solution compositions were $\mathrm{HF}\left(12.0 \mathrm{~mol} \mathrm{kgw}^{-1}\right)-\mathrm{HNO}_{3}\left(1.9 \mathrm{~mol} \mathrm{kgw}^{-1}\right)$ for the ISCz-1 sample and $\mathrm{HF}\left(3.0 \mathrm{~mol} \mathrm{kgw}^{-1}\right)-\mathrm{HNO}_{3}(1.9 \mathrm{~mol} \mathrm{kgw}$ ) for the illite/smectite samples from the Shinzan area, respectively. A higher HF concentration was necessary in the case of the ISCz-1 sample compared with the other samples because of the presence of a relatively high amount of quartz (5.85 wt.\% at dry state, Table 4) in the ISCz-1 sample. The compositions of the acid solutions were optimized to obtain the complete dissolution of the samples after stirring at $540 \mathrm{rpm}$ for approximately $3 \mathrm{~h}$. For the series of $\mathrm{I} / \mathrm{S}$ samples from the Shinzan area, approximately $20-30 \mathrm{mg}$ of samples were dissolved in $50 \mathrm{~mL}$ of the $\mathrm{HF}-\mathrm{HNO}_{3}$ acid solution. For the dehydrated ISCz-1 sample, the amount of sample was approximately $40 \mathrm{mg}$ for $50 \mathrm{~mL}$ of the $\mathrm{HF}-\mathrm{HNO}_{3}$ acid solution. The weighing of this latter sample and the filling of the sample vessel were conducted in a glove box under a dry argon atmosphere in order to prevent the hydration of the sample. 
Table 7. Origin and purity of the chemical reagents and the secondary references used for the solution calorimetry experiments.

\begin{tabular}{|c|c|c|c|c|c|c|}
\hline Name & Formula & CAS number & Source & $\begin{array}{l}\text { Titration } \\
10^{2} w^{\mathrm{a}} \\
\end{array}$ & $\begin{array}{l}\text { Mole fraction } \\
\text { purity }\end{array}$ & $\begin{array}{l}\text { Analysis } \\
\text { methods }\end{array}$ \\
\hline Acid solutions & & & & & & \\
\hline $\begin{array}{l}\text { Hydrochloric acid } 37 \% \text {, } \\
\text { AnalaR Normapur }\end{array}$ & $\mathrm{HCl}$ & 7647-01-0 & VWR & 36.3 & & $N / A^{b}$ \\
\hline $\begin{array}{l}\text { Hydrofluoric acid } 40 \% \text {, } \\
\text { AnalaR Normapur }\end{array}$ & HF & 7664-39-3 & VWR & 40.4 & & $N / A^{b}$ \\
\hline $\begin{array}{l}\text { Nitric acid } 69 \% \text {, } \\
\text { AnalaR Normapur }\end{array}$ & $\mathrm{HNO}_{3}$ & $7697-37-2$ & VWR & 69.7 & & $N / A^{b}$ \\
\hline THAM $^{\mathrm{C}}$, ACS reagent & $\mathrm{NH}_{2} \mathrm{C}\left(\mathrm{CH}_{2} \mathrm{OH}\right)_{3}$ & $77-86-1$ & Alfa Aesar & & $\geq 0.998$ & $N / A^{b}$ \\
\hline Secondary references & & & & & & \\
\hline Gibbsite & $\mathrm{Al}(\mathrm{OH})_{3}$ & $14762-49-3$ & Baker & & $\geq 0.99$ & PXRD $^{d}$ \\
\hline Quartz- $\alpha$ & $\mathrm{SiO}_{2}$ & $14808-60-7$ & $\begin{array}{l}\text { Natural } \\
\text { BRGM's } \\
\text { collection }^{\mathrm{e}}\end{array}$ & & $\geq 0.99$ & $\begin{array}{l}\text { PXRD }^{d} \\
\text { Rietveld } \\
\text { analysis }\end{array}$ \\
\hline Goethite & $\mathrm{FeOOH}$ & $20344-49-4$ & $\begin{array}{l}\text { Natural } \\
\text { BRGM's } \\
\text { collection }^{\mathrm{e}}\end{array}$ & & $\geq 0.99$ & PXRD $^{d}$ \\
\hline Iron(II) oxide & $\mathrm{FeO}$ & $1345-25-1$ & Sigma-Aldrich & & 0.999 & $N / A^{b}$ \\
\hline Calcium hydroxide & $\mathrm{Ca}(\mathrm{OH})_{2}$ & $1305-62-0$ & Merck & & $\geq 0.96$ & PXRD $^{d}$ \\
\hline Magnesium hydroxide & $\mathrm{Mg}(\mathrm{OH})_{2}$ & $1317-43-7$ & Fluka & & $\geq 0.99$ & $N / A^{b}$ \\
\hline Potassium nitrate & $\mathrm{KNO}_{3}$ & 7757-79-1 & Sigma-Aldrich & & $\geq 0.99$ & $N / A^{b}$ \\
\hline Rutile & $\mathrm{TiO}_{2}$ & $13463-67-7$ & ChemPur & & 0.995 & $N / A^{b}$ \\
\hline
\end{tabular}

\subsubsection{Standard enthalpy of formation of a clay mineral from constituents at $298.15 \mathrm{~K}$}

The experimental method described in Gailhanou et al. $[25,26]$ was used for the determination of the enthalpy of formation of the illite/smectite in the ISCz-1 sample. This method was based on a set of dissolution reactions that were performed in order to obtain the enthalpy of formation of the clay mineral from secondary references, i.e. constituents chosen among oxides, hydroxides and nitrates, at $298.15 \mathrm{~K}$. The source and purity of each secondary reference used for the solution calorimetry experiments are described in Table 7. The reactions involved were (i) the dissolution of the clay sample containing the clay mineral and impurities, (ii) the dissolution of a mixture composed of the constituents and impurities with the same composition as those present in the sample and (iii) dilution type reactions. The masses of the constituents (except $\mathrm{H}_{2} \mathrm{O}$ ) and impurities are calculated to present the elemental stoichiometry of $40 \mathrm{mg}$ of the anhydrous 
clay sample. The impurities were added to the mixture of constituents in the same amounts as those present in the clay sample. The weightings were realized in an air atmosphere for better stability of the balance with a maximum deviation of $10 \mu \mathrm{g}$. Thus, approximately $46 \mathrm{mg}$ of a mechanical mixture of constituents and impurities was made for each dissolution experiment to accurately determine the amounts of each of these compounds present in the mixture. Four or five measurements of enthalpies of dissolution were performed on each clay sample and constituent and impurity mixtures. The relative uncertainties for the enthalpy values are lower than $0.5 \%$. For a given sample, slight variations in the final solution composition existed due to the slight variations in the sample mass. However, no dependency of the enthalpy of dissolution (per unit mass) on these variations of solution composition was observed.

The reaction of the formation of a clay mineral from the constituents is expressed by the following (Gailhanou et al. [26]):

$\sum_{i} n_{i}$ constituent ${ }_{i}^{*}+n_{\mathrm{H}_{2} \mathrm{O}} \mathrm{H}_{2} \mathrm{O} \rightarrow$ clay, $\mathrm{H} \mathrm{H}_{2} \mathrm{O}+n_{\mathrm{HNO}_{3}} \mathrm{HNO}_{3}$ (Reaction 1)

The superscript $\left(^{*}\right)$ refers to all constituents except $\mathrm{H}_{2} \mathrm{O}, n_{i}$ is the amount of the constituent $i$ (in $\mathrm{mol} / \mathrm{mol}$ of clay), $n_{\mathrm{H} 2 \mathrm{O}}$ is the amount of the constituent $\mathrm{H}_{2} \mathrm{O}$, obtained indirectly from the balance on the $\mathrm{O}$ and $\mathrm{H}$ elements, $n$ is the amount of water adsorbed in the clay, and $n_{\mathrm{HNO}}$ is the amount of $\mathrm{HNO}_{3}$ calculated from the balance of nitrates.

Therefore, the enthalpy of formation of the clay mineral from constituents $\Delta H_{f / c o n s i t}^{0}$, expressed in $\mathrm{kJ} \mathrm{mol}^{-1} \mathrm{O}_{10}(\mathrm{OH})_{2}$, may be calculated according to the following formula (Eq. (1)) described in Gailhanou et al. [26]:

$$
\begin{aligned}
\Delta H_{f / c o n s i t}^{0}= & \left(\frac{M_{\min }}{\eta}+\left(n-n_{\mathrm{H}_{2} \mathrm{O}}\right) M_{\mathrm{H}_{2} \mathrm{O}}+n_{\mathrm{HNO}_{3}} M_{\mathrm{HNO}_{3}}\right) \Delta H_{\text {diss }, \text { mixt }}-\left(\frac{M_{\min }}{\eta}+n M_{\mathrm{H}_{2} \mathrm{O}}\right) \Delta H_{\text {diss sample }} \\
& +n_{\mathrm{H}_{2} \mathrm{O}} M_{\mathrm{H}_{2} \mathrm{O}} \Delta H_{\text {dil }}-n_{\mathrm{HNO}_{3}} M_{\mathrm{HNO}_{3}} \Delta H_{\text {sol }}
\end{aligned}
$$

where $M_{\min }$ is the molar mass of the dehydrated clay mineral, $\eta$ is the mass fraction of the dehydrated clay in the dehydrated sample, $\Delta H_{\text {diss,mixt }}$ is the enthalpy of dissolution of the mixture of constituents and impurities (in $\mathrm{J} \mathrm{g}^{-1}$ ), and $\Delta H_{\text {diss,sample }}$ is the enthalpy of dissolution of the clay sample (in $\mathrm{J} \mathrm{g}^{-1}$ ). $\Delta H_{d i l}$ and $\Delta H_{\text {sol }}$ are expressed in $\mathrm{J} \mathrm{g}^{-1}$ and are the enthalpy of the dilution of the $\mathrm{HF}-\mathrm{HNO}_{3}$ solution and the integral enthalpy of the mixing of pure $\mathrm{HNO}_{3}$ in the $\mathrm{HF}-\mathrm{HNO} 3$ solution, respectively. 
Finally, the standard enthalpy of formation $\Delta H_{f}^{0}$ of the illite/smectite mineral was determined by considering $\Delta H_{f / c o n s t i t}^{0}$ and the standard enthalpies of formation of the chosen secondary references (see Appendix $\mathrm{C}$ for these latter data).

\section{Results}

\subsection{Thermodynamic properties of anhydrous illite-smectite ISCz-1}

\subsubsection{Heat capacities}

The heat capacities measured for the Ca-saturated ISCz-1 sample are plotted between 2 and $330 \mathrm{~K}$ for the PPMS data and between 300 and $520 \mathrm{~K}$ for the DSC data (Fig. 5). All the raw data are given in Appendix A. A significant discrepancy between the measurements performed by both techniques appears in the common temperature range $300-330 \mathrm{~K}$. By comparison with the $C_{p}$ data previously obtained for the $\mathrm{Na}$ saturated ISCz-1 sample [33], the $C_{p}$ values measured by the DSC increase similarly, whereas the $C_{p}$ values from the PPMS tend to drastically depart from the general trend between approximately $230 \mathrm{~K}$ and $330 \mathrm{~K}$. This comparison with the Na-saturated ISCz-1 sample reveals the inaccuracy of the $C_{p}$ values measured by the PPMS at the highest temperature range. This could possibly be due to the low thermal conductivity of the sample. Indeed, Kennedy et al. [47] tested the reliability of the PPMS technique on several phases and noticed that the $C_{p}$ data could be precise but inaccurate at high temperatures ( $\left.T>150 \mathrm{~K}\right)$, particularly in the case of poor thermal conductor phases. Therefore, the heat capacities were fitted between $200 \mathrm{~K}$ and $520 \mathrm{~K}$ based on PPMS data from $170 \mathrm{~K}$ and $200 \mathrm{~K}$ and DSC data from $300 \mathrm{~K}$ and $520 \mathrm{~K}$, using a least-square fit method and the polynomial function $C_{p}(T)=2.7070-3.1540 \cdot 10^{-4} T+1.2571 \cdot 10^{4} T^{-2}-33.827 T^{-0.5}$. The relative errors for the least square fit method are lower than $1.5 \%$ at $\mathrm{T}>300 \mathrm{~K}$. 


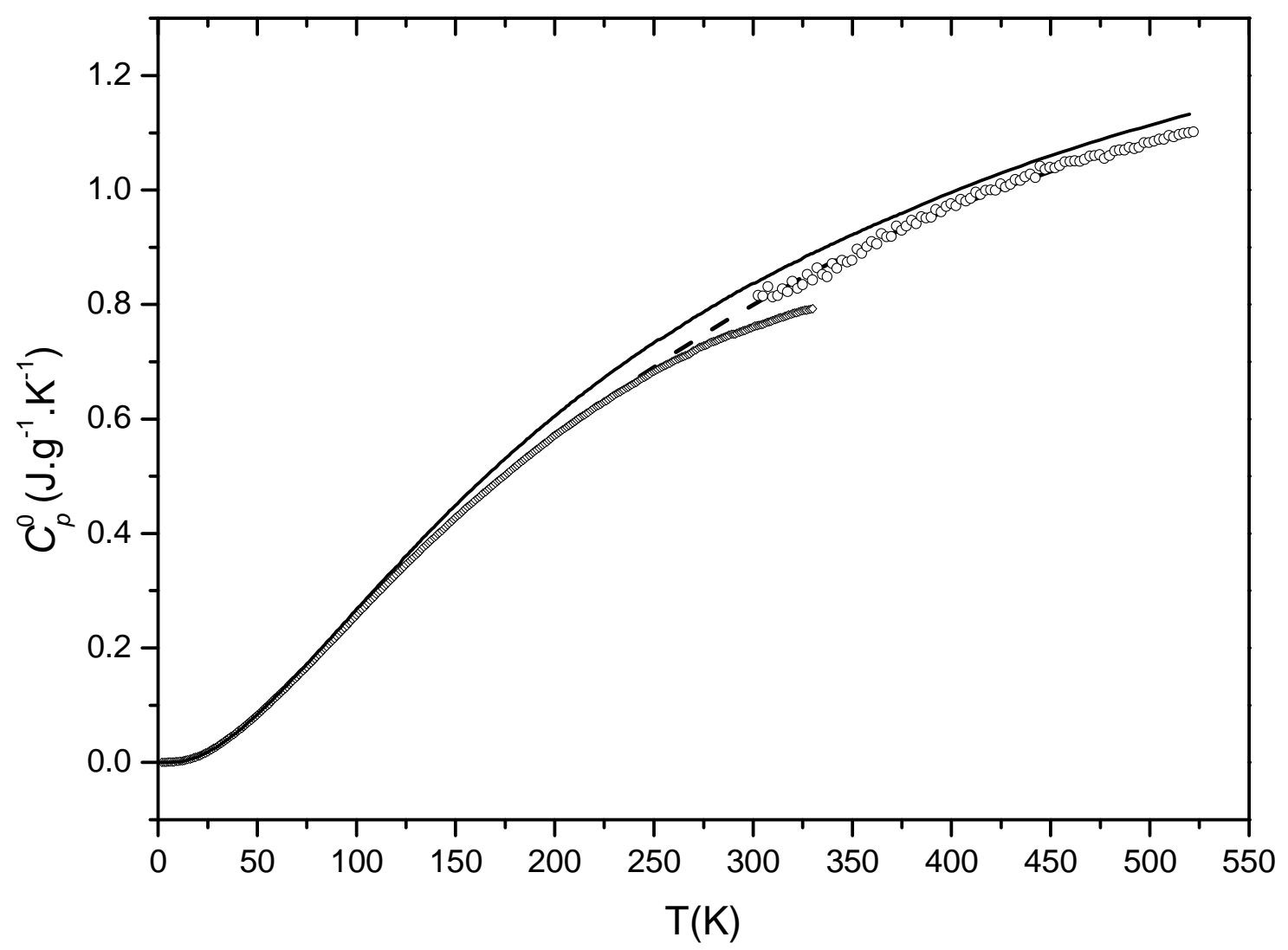

Fig. 5. Heat capacities measured for the ISCz-1(Ca) sample (diamonds are values obtained by PPMS for sample 2 , circles are values obtained by DSC, and the dashed line represents interpolated data) and the ISCz-1(Na) sample (line represents data from Gailhanou et al., 2007) between $2 \mathrm{~K}$ and $520 \mathrm{~K}$.

The heat capacities of the sample are linearly interpolated at every degree between $0 \mathrm{~K}$ and $520 \mathrm{~K}$. The heat capacities of the interstratified mineral are then calculated from the heat capacities of the sample by subtracting the contributions of the impurities (Table 4, Amounts in dry sample) according to the method described in [33]. The heat capacity data for the impurities are taken from the literature (see references in Appendix B). Due to the lack of thermodynamic data for the bernalite $\left(\mathrm{Fe}(\mathrm{OH})_{3}\right)$ mineral, this latter was assimilated to goethite $(\mathrm{FeOOH})$ for the correction calculations. Therefore, the amount of goethite considered in the following text was adjusted to 0.98 wt.\%, with respect to the total amount of $\mathrm{Fe}$ in goethite and bernalite. Furthermore, the heat capacity data for goethite provided by Majzlan et al. [48] are limited to the temperature range $0-375 \mathrm{~K}$ due to the occurrence of the magnetic Neel transition at approximately $375 \mathrm{~K}$. 
Consequently, the correction of the heat capacities of the sample is performed between 0-375 K. The heat capacities of the interstratified mineral $C_{p, m}^{0}$ expressed in $\mathrm{J} \mathrm{K}^{-1} \mathrm{~mol}^{-1}$ are given in Table 8 for this temperature range.

\subsubsection{Heat contents}

The heat contents of the mineral, $H^{0}(T)-H^{0}(298.15 K)$, are calculated at any temperature by the integration of the $C_{p, m}^{0}$ function according to (Eq. (2))

$$
H^{0}(T)-H^{0}(298.15 K)=\int_{298.15}^{T} C_{p, m}^{0} d T
$$

using the trapezoid method at every degree (Table 8).

\subsubsection{Entropy}

The third-law entropy of the interstratified mineral $S^{0}$ is expressed by (Eq. (3))

$S^{0}=\int_{0}^{T} \frac{C_{p, m}^{0}}{T} d T+S^{0(\text { resid. })}$

where $S^{0(c a l)}=\int_{0}^{T} \frac{C_{p, m}^{0}}{T} d T$ is the calorimetric entropy obtained directly from heat capacity measurements, and $S^{\text {(resio) }}$ is the residual entropy. This latter term is not available from the calorimetric measurements and requires additional structural information about the mineral (Ulbrich and Waldbaum [49]). The chemical site configurational entropy $S^{0(c o n f)}$ that is associated with cationic disorder in the tetrahedral, octahedral and interlayer crystallographic sites is a significant part of the residual entropy. It is assessed according to the method described by Blanc et al. [1]. The residual entropy may also include a magnetic term $S^{0(m a g)}$ that is associated with the disordering of the magnetic spins of the transition metals in the clay minerals that occurs at very low temperatures (e.g., $\mathrm{T}<10 \mathrm{~K}$ for iron-bearing chlorites, [50]). Indeed, for clay minerals, a recent study [51] has shown that the magnetic contribution is difficult to detect and directly measure. The maximum value of the magnetic entropy is assessed by using the method described by Ulbrich and Waldbaum [49]. It is based on the maximum number of spin configurations as follows:

$S^{0(m a g)}=R \sum_{i} x_{i} \ln \left(2 S_{i}+1\right)$ 
where $R$ is the gas constant, $x_{i}$ the amount of element $i$ and $S_{i}$ its spin number (for $\mathrm{Fe}^{3+}, S=5 / 2$; for $\mathrm{Fe}^{2+}$, $S=2$ ). Finally, in the case of the illite-smectite ISCz-1 mineral, the configurational entropy $S^{0(\text { conf })}$ is estimated at $29.53 \mathrm{~J} \mathrm{~K}^{-1} \mathrm{~mol}^{-1}$ and the maximum magnetic entropy is estimated at $0.58 \mathrm{~J} \mathrm{~K}^{-1} \mathrm{~mol}^{-1}$. The calorimetric entropy data are given in Table 8. 
Table 8. Standard molar heat capacities and derived thermodynamic functions of the dehydrated Ca-saturated illitesmectite ISCz-1 mineral (corrected for impurities) at selected temperatures.

\begin{tabular}{cccc}
\hline $\mathrm{T} / \mathrm{K}^{\mathrm{a}}$ & $C_{p, m}^{0}(T)^{\mathrm{b}}$ & $S^{(0) \mathrm{calb}}$ & $H^{0}(T)-H^{0}(298.15)^{\mathrm{b}}$ \\
& $\mathrm{J} \mathrm{K} \mathrm{K}^{-1} \mathrm{~mol}^{-1}$ & $\mathrm{~J} \mathrm{~K} \mathrm{~K}^{-1} \mathrm{~mol}^{-1}$ & $\mathrm{~kJ} \mathrm{~mol}^{-1}$ \\
\hline 0 & 0.00 & 0.00 & -45.596 \\
10 & 0.65 & 0.42 & -45.594 \\
20 & 3.81 & 1.65 & -45.574 \\
30 & 10.61 & 4.37 & -45.505 \\
40 & 19.85 & 8.64 & -45.354 \\
50 & 30.53 & 14.20 & -45.103 \\
60 & 43.01 & 20.85 & -44.736 \\
70 & 55.96 & 28.44 & -44.242 \\
80 & 69.39 & 36.78 & -43.616 \\
90 & 83.08 & 45.75 & -42.853 \\
100 & 97.33 & 55.24 & -41.951 \\
110 & 111.25 & 65.17 & -40.908 \\
120 & 124.93 & 75.43 & -39.728 \\
130 & 138.00 & 85.95 & -38.413 \\
140 & 150.81 & 96.66 & -36.968 \\
150 & 163.30 & 107.49 & -35.397 \\
160 & 175.05 & 118.41 & -33.704 \\
170 & 186.45 & 129.37 & -31.896 \\
180 & 197.55 & 140.34 & -29.976 \\
190 & 208.35 & 151.31 & -27.946 \\
200 & 216.66 & 162.25 & -25.812 \\
210 & 226.42 & 173.06 & -23.597 \\
220 & 236.19 & 183.82 & -21.284 \\
230 & 245.88 & 194.53 & -18.873 \\
240 & 255.41 & 205.20 & -16.367 \\
250 & 264.72 & 215.81 & -13.766 \\
260 & 273.81 & 226.38 & -11.073 \\
270 & 282.64 & 236.88 & -8.291 \\
280 & 291.20 & 247.31 & -5.421 \\
290 & 299.49 & 257.67 & -2.468 \\
298.15 & 306.05 & 266.06 & 0.000 \\
300 & 307.51 & 267.96 & 0.568 \\
310 & 315.23 & 278.17 & 3.682 \\
320 & 322.66 & 288.30 & 6.871 \\
330 & 329.83 & 298.34 & 10.134 \\
340 & 336.73 & 308.29 & 13.467 \\
350 & 343.37 & 318.14 & 16.868 \\
360 & 349.78 & 327.91 & 20.334 \\
370 & 355.95 & 337.58 & 23.862 \\
375 & 358.95 & 342.37 & 25.650 \\
\hline
\end{tabular}

${ }^{a}$ Standard uncertainties $u$ are $u(T)=0.01 \mathrm{~K}(2<T / \mathrm{K}<300)$ and $u(T)=0.05 \mathrm{~K}(300<T / \mathrm{K}<375)$.

${ }^{\mathrm{b}}$ The relative expanded uncertainties with level of confidence $0.95(k=2)$ are: $U_{r}\left(C_{p, m}^{\circ}\right)=0.05(2<T / \mathrm{K}<50)$, $U_{r}\left(C_{p, m}^{\circ}\right)=0.02(50<T / K<298)$ and $U_{r}\left(C_{p, m}^{\circ}\right)=0.015(298<T / K<375), U_{r}\left(S^{(0) c a l}\right)=0.05(2<T / K<75)$, $U_{r}\left(S^{(0) c a l}\right)=0.04(75<T / K<110)$ and $U_{r}\left(S^{(0) c a l}\right)=0.03(110<T / K<375), U_{r}\left(H^{\rho}(T)-H^{\rho}(298.15)\right)=0.05(2<T / K<50)$ and $U_{r}\left(H^{P}(T)-H^{P}(298.15)\right)=0.02(50<T / K<375)$. 


\subsubsection{Standard enthalpy of formation}

The enthalpies of dissolution of the Ca-saturated ISCz-1 sample and the constituents* mixture (superscript * means: except $\mathrm{H}_{2} \mathrm{O}$ constituent) are given in Table 9. The uncertainties associated with the mean enthalpies are calculated from the measured values using the Student's $t$-distribution with a 95 percent confidence interval.

Table 9. Enthalpies of dissolution of the dehydrated ISCz-1 sample and of the corresponding mixtures of constituents* and impurities $\left(^{*}=\right.$ except $\mathrm{H}_{2} \mathrm{O}$ constituent) measured in $50 \mathrm{~mL}$ of a $\mathrm{HF}\left(12.0 \mathrm{~mol} \mathrm{kgw}^{-1}\right)-\mathrm{HNO}_{3}\left(1.9 \mathrm{~mol} \mathrm{kgw}^{-1}\right)^{\mathrm{a}}$ solution, at $298.15 \mathrm{~K}$ and at ambient pressure of $101 \mathrm{kPa}$.

\begin{tabular}{|c|c|c|c|}
\hline Sample & $\begin{array}{c}\text { Sample mass } \\
\qquad \mathrm{m}_{\mathrm{s}} / \mathrm{mg}\end{array}$ & $\begin{array}{l}\Delta H_{\text {diss }} \\
/ \mathrm{J} \mathrm{g}^{-1}\end{array}$ & $\begin{array}{l}\text { Mean } \Delta H_{\text {diss }} \\
\quad / \mathrm{J} \mathrm{g}^{-1}\end{array}$ \\
\hline $\begin{array}{c}\text { Dehydrated } \\
\text { sample ISCz-1 }\end{array}$ & $\begin{array}{l}39.86 \\
40.01 \\
40.00 \\
40.20 \\
\end{array}$ & $\begin{array}{l}-2256.60 \\
-2257.62 \\
-2258.31 \\
-2258.74\end{array}$ & $-2257.82 \pm 1.19^{c}$ \\
\hline $\begin{array}{c}\text { Mixture of } \\
\text { constituents } \\
\text { impurities }\end{array}$ & $\begin{array}{l}46.58 \\
46.55 \\
46.55 \\
46.57 \\
46.55 \\
\end{array}$ & $\begin{array}{l}-1845.16 \\
-1849.41 \\
-1850.65 \\
-1845.16 \\
-1850.00 \\
\end{array}$ & $-1848.08 \pm 3.28^{c}$ \\
\hline $\begin{array}{l}\text { a } \mathrm{kgw}=\text { kilogram of } \mathrm{w} \\
\mathrm{o} \\
\text { Standard uncertaint } \\
\text { The expanded unce }\end{array}$ & are calculated & $\begin{array}{l}3 \mathrm{kPa} . \\
\text { Student's }\end{array}$ & \\
\hline
\end{tabular}

The enthalpy of dilution $\Delta H_{\text {dil }}$ and the solution enthalpy $\Delta H_{\text {sol }}$ associated with the mixing of pure $\mathrm{HNO}_{3}$ in $\mathrm{HF}\left(12.0 \mathrm{~mol} \mathrm{kgw}^{-1}\right)-\mathrm{HNO}_{3}\left(1.9 \mathrm{~mol} \mathrm{kgw}^{-1}\right)$ were determined by Gailhanou et al. [25]. Their values were $-1.57 \pm 0.30 \mathrm{~kJ} \mathrm{~mol}^{-1} \mathrm{H}_{2} \mathrm{O}$ and $-27.7 \pm 7.5 \mathrm{~kJ} \mathrm{~mol}^{-1} \mathrm{HNO}_{3}$, respectively.

Afterwards, the enthalpy of formation of the mineral from the constituents was then calculated using (Eq. (1)) (Table 10). 
Table 10. Reaction of the formation of illite-smectite ISCz-1 from the secondary reference constituents and the

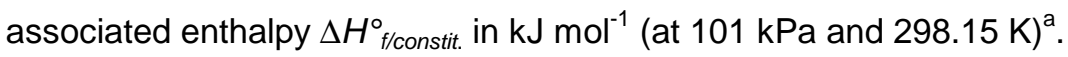

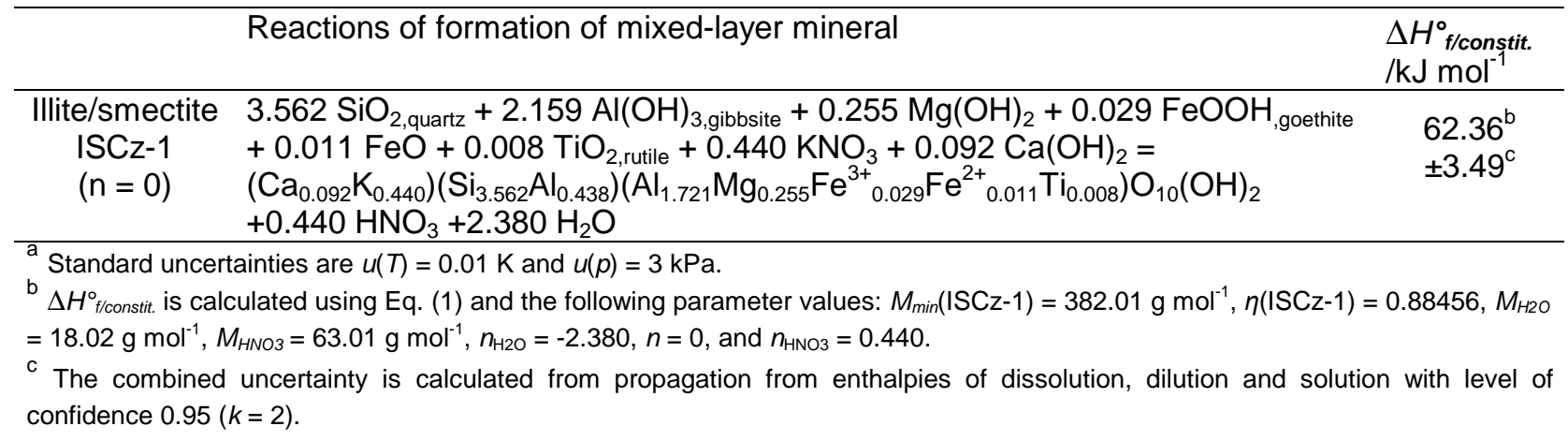

Eventually, the standard enthalpy of formation of the illite-smectite $\Delta H_{f}^{0}$ was obtained from the enthalpy of formation of the mineral from the secondary reference constituents and from the standard enthalpies of formation of these reference constituents (Table 11). These latter values are selected consistently with the Thermochimie database [27] at $298.15 \mathrm{~K}$ and are tabulated in Appendix C.

The expanded uncertainty associated with $\Delta H_{f}^{0}$ at approximately 95 percent confidence limits was calculated using the error propagation method [52]:

$\Delta\left(\Delta H_{f}^{0}\right)=\sqrt{\left[\Delta\left(\Delta H_{f / \text { constit. }}^{0}\right)\right]^{2}+\sum_{i} v_{i}^{2}\left[\Delta\left(\Delta H_{f}^{\text {constit. } i}\right)\right]^{2}}$

where $v_{i}$ is the stoichiometric coefficient associated with the constituent $i$, and $\Delta H_{f}^{\text {constit.i }}$ is the standard enthalpy of formation of the constituent $i$. The expanded uncertainties associated with $\Delta H_{f / c o n s t i t}^{0}$. and $\Delta H_{f}^{\text {constit.i }}$ correspond to two standard deviations of the mean.

\subsubsection{Standard Gibbs free energy of formation}

The standard Gibbs free energy of formation $\Delta G_{f}^{0}$ is expressed by the following:

$\Delta G_{f}^{0}(T)=\Delta H_{f}^{0}(T)-T \Delta S_{f}^{0}(T)$

where $\Delta S_{f}^{0}(T)$ is the standard entropy of formation of the interstratified mineral that was calculated considering the reaction of the formation of the mineral from the elements in their stable thermodynamic form in standard conditions. The value for the ISCz-1 mineral was obtained at $298.15 \mathrm{~K}$ from the third-law entropy of the mineral $S^{0}$ (Table 11) and from the entropies of the elements at $298.15 \mathrm{~K}$. These latter data were taken from Cox et al. [53] for $\mathrm{Si}_{(\mathrm{cr})}, \mathrm{Al}_{(\mathrm{cr})}, \mathrm{Mg}_{(\mathrm{cr})}, \mathrm{Ti}_{(\mathrm{cr})}, \mathrm{K}_{(\mathrm{cr})}, \mathrm{Ca}_{(\mathrm{cr})}, \mathrm{O}_{2(\mathrm{~g})}$, and $\mathrm{H}_{2(\mathrm{~g})}$ and from Chase [54] for $\mathrm{Fe}_{(\mathrm{cr})}$. 
3.2. Synthesis of the thermodynamic properties of anhydrous illite-smectite ISCz-1

The complete set of thermodynamic properties of the interstratified ISCz-1 mineral at $298.15 \mathrm{~K}$ and ambient pressure of $101 \mathrm{kPa}$ is given in Table 11. Since its structural formula contains a small amount of $\mathrm{TiO}_{2}$, a simplified structural formula is also proposed in order to ease the introduction of the phase into geochemical databases. The simplification is based on the fictive solid-solid reactions with properties of reaction equal to 0 . In the case of the interstratified ISCz-1, the following fictive reaction was considered:

$\left(\mathrm{Ca}_{0.092} \mathrm{~K}_{0.440}\right)\left(\mathrm{Si}_{3.562} \mathrm{Al}_{0.438}\right)\left(\mathrm{Al}_{1.721} \mathrm{Mg}_{0.255} \mathrm{Fe}^{3+}{ }_{0.029} \mathrm{Fe}^{2+}{ }_{0.011} \mathrm{Ti}_{0.008}\right) \mathrm{O}_{10}(\mathrm{OH})_{2}+0.0055 \mathrm{Al}_{2} \mathrm{O}_{3}=$

$\left(\mathrm{Ca}_{0.092} \mathrm{~K}_{0.439}\right)\left(\mathrm{Si}_{3.562} \mathrm{Al}_{0.438}\right)\left(\mathrm{Al}_{1.732} \mathrm{Mg}_{0.255} \mathrm{Fe}^{3+}{ }_{0.029} \mathrm{Fe}^{2+}{ }_{0.011}\right) \mathrm{O}_{10}(\mathrm{OH})_{2}+0.0005 \mathrm{~K}_{2} \mathrm{O}+0.008 \mathrm{TiO}_{2}$

(Reaction 2)

The thermodynamic data for alumina- $\alpha$, rutile and $\mathrm{K}_{2} \mathrm{O}$ are taken from the Thermoddem database (http://thermoddem.brgm.fr, [28]). 
Table 11. Standard thermodynamic properties of the dehydrated illite-smectite ISCz-1 mineral at $298.15 \mathrm{~K}$.

\begin{tabular}{|c|c|c|c|c|c|c|c|c|c|c|c|c|}
\hline \multicolumn{9}{|c|}{$\mathrm{T}=298.15 \mathrm{~K}^{\mathrm{a}}$} & \multirow{3}{*}{$\begin{array}{l}\mathrm{A} \\
/ \mathrm{J} \mathrm{K}^{-1} \mathrm{~mol}^{-1}\end{array}$} & \multirow{2}{*}{$\begin{array}{l}\mathrm{B}^{*} 10^{3} \\
/ \mathrm{J} \mathrm{K}^{-2} \mathrm{~mol}^{-1}\end{array}$} & \multirow{2}{*}{$\begin{array}{l}\mathrm{C}^{*} 10^{-5} \\
/ \mathrm{K} \mathrm{mol}^{-1}\end{array}$} & \multirow{2}{*}{$\begin{array}{l}\begin{array}{l}T \text { range for } C_{p} \\
\text { functions }{ }^{b}\end{array} \\
T / \mathrm{K}\end{array}$} \\
\hline Mineral & $\Delta G_{f}^{0}$ & $\Delta H_{f}^{0}$ & $S^{(\text {callo } 0}$ & $S^{\text {(cont)0 }}$ & $S^{(m a g) 0}$ & $S^{0}$ & $V^{p e}$ & $C_{p}^{0}(298.15 \mathrm{~K})$ & & & & \\
\hline & $/ \mathrm{kJ} \mathrm{mol}^{-1}$ & $/ \mathrm{kJ} \mathrm{mol}^{-1}$ & $/ \mathrm{J} \mathrm{K}^{-1} \mathrm{~mol}^{-1}$ & $/ \mathrm{J} \mathrm{K}^{-1} \mathrm{~mol}^{-1}$ & $/ \mathrm{J} \mathrm{K}^{-1} \mathrm{~mol}^{-1}$ & $/ \mathrm{J} \mathrm{K}^{-1} \mathrm{~mol}^{-1}$ & $/ \mathrm{cm}^{3} \mathrm{~mol}^{-1}$ & $/ \mathrm{J} \mathrm{K}^{-1} \mathrm{~mol}^{-1}$ & & & & \\
\hline \multirow[t]{2}{*}{$\begin{array}{l}\text { Illite/smectite } \\
\text { ISCz-1 }\end{array}$} & $\begin{array}{l}-5417.38 \\
\pm 7.72^{c}\end{array}$ & $\begin{array}{l}-5785.74 \\
\pm 7.46^{c}\end{array}$ & $\begin{array}{l}266.06 \\
\pm 6.00^{d}\end{array}$ & 29.53 & 0.58 & $\begin{array}{l}296.17 \\
\pm 6.00^{d}\end{array}$ & 137.13 & $306.05 \pm 4.59^{d}$ & 228.34 & 438.31 & -47.04 & $298-375$ \\
\hline & \multicolumn{8}{|c|}{ Properties recalculated for a simplified structural formula ${ }^{\dagger}$} & & & & \\
\hline $\begin{array}{l}\text { Illite/smectite } \\
\text { ISCz-1* }\end{array}$ & $\begin{array}{l}-5418.62 \\
\pm 7.72^{\mathrm{c}}\end{array}$ & $\begin{array}{l}-5787.22 \\
\pm 7.46^{c}\end{array}$ & $\begin{array}{l}265.89 \\
\pm 6.00^{9}\end{array}$ & 28.89 & 0.58 & $\begin{array}{l}295.36 \\
\pm 6.00^{9}\end{array}$ & 137.13 & $306.00 \pm 4.59^{9}$ & 236.14 & 422.80 & -49.92 & $298-375$ \\
\hline
\end{tabular}

${ }^{a}$ The standard uncertainty is $u(T)=0.05 \mathrm{~K}$.

${ }^{\mathrm{b}}$ Between 298 and $375 \mathrm{~K}$, the $C_{p}(T)$ functions are expressed according to $C_{p}(T)=A+B 10^{-3} T+C 10^{5} T^{-2}$, where $A, B$ and $C$ are Maier-Kelley coefficients obtained by fitting the $C_{p}$ curves.

${ }^{c}$ The combined uncertainties $U\left(\Delta H_{f}^{\circ}\right)$ and $U\left(\Delta G_{f}^{\circ}\right)$ are calculated from propagation from enthalpy (Eq. 5) and from enthalpy and entropy (Eq. 6), respectively, with level of confidence $0.95(k=2)$.

${ }^{d}$ The relative expanded uncertainties in the property values are $U_{r}\left(C_{p, m}^{\circ}\right)=0.015$ and $U_{r}\left(S^{(0) c a l}\right)=0.03$ at approximately 95 percent confidence limits.

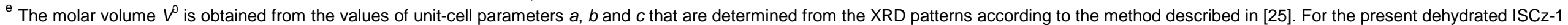
sample, $a=5.20 \AA, b=9.01 \AA$ and $c=10.12 \AA$.

${ }^{\mathrm{f}}$ The simplified formula is introduced to ease the predictive calculations and their implementation into databases. The simplification process is detailed in the text.

Illite/smectite ISCz-1: $\left(\mathrm{Ca}_{0.092} \mathrm{~K}_{0.440}\right)\left(\mathrm{Si}_{3.562} \mathrm{Al}_{0.438}\right)\left(\mathrm{Al}_{1.721} \mathrm{Mg}_{0.255} \mathrm{Fe}^{3+}{ }_{0.029} \mathrm{Fe}^{2+}{ }_{0.011} \mathrm{Ti}_{0.008}\right) \mathrm{O}_{10}(\mathrm{OH})_{2}$

Illite/smectite ISCz-1*: $\left(\mathrm{Ca}_{0.092} \mathrm{~K}_{0.439}\right)\left(\mathrm{Si}_{3.562} \mathrm{Al}_{0.438}\right)\left(\mathrm{Al}_{1.732} \mathrm{Mg}_{0.255} \mathrm{Fe}^{3+}{ }_{0.029} \mathrm{Fe}^{2+}{ }_{0.011}\right) \mathrm{O}_{10}(\mathrm{OH})_{2}$.

${ }^{g}$ The combined uncertainties $U\left(C_{p, m}^{\circ}\right)$ and $U\left(S^{(0) c a l}\right)$ are calculated from propagation from reaction (2) with level of confidence $0.95(k=2)$. 


\subsection{Enthalpies of mixing for mixed-layers from Shinzan area samples}

The analysis of the chemical dispersions among the illite-smectite compositions (Fig. 4) shows that all of these can be described by a ternary solid solution with illite $\mathrm{N}$, montmorillonite $\mathrm{A}$ and illite-smectite $\mathrm{F}$ end members. Although the chemical dispersions mostly occur along the illite - smectite join, the ternary solid solution is preferred to the binary illite-smectite solid solution for accuracy reasons. Since the enthalpies of mixing are expected to be very low and consequently difficult to determine accurately given their associated uncertainties, it is preferable to perform the measurements for all samples without adding a supplementary source of uncertainty induced by the consideration of the binary solid solution. In the following, the enthalpies of mixing for the illite-smectite compositions from the Shinzan area samples are determined by using isothermal dissolution calorimetry at $298.15 \mathrm{~K}$.

\subsubsection{Enthalpies of dissolution at $298.15 \mathrm{~K}$}

The enthalpies of dissolution of all the samples in $\mathrm{HF}\left(3.0 \mathrm{~mol} \mathrm{kgw}{ }^{-1}\right)-\mathrm{HNO}_{3}\left(1.9 \mathrm{~mol} \mathrm{kgw}^{-1}\right)$ at $25^{\circ} \mathrm{C}$ were measured by Perbost et al. [41]. The data are given in Table 12. The uncertainties associated with the mean enthalpies are calculated from the measured values using the Student's $t$-distribution with a 95 percent confidence interval. The relative expanded uncertainties are lower than $1 \%$, except for sample $E$, for which it is $2.4 \%$. 
Table 12. Mean values of the enthalpies of dissolution of the I/S samples from the Shinzan area measured by [41] in a $\mathrm{HF}\left(3.0 \mathrm{~mol} \mathrm{kgw}^{-1}\right)-\mathrm{HNO}_{3}\left(1.9 \mathrm{~mol} \mathrm{kgw}^{-1}\right)$ solution at $298.15 \mathrm{~K}$ and at ambient pressure of $101 \mathrm{kPa}^{\mathrm{a}}$. Mnt $\mathrm{A}=$ Montmorillonite A.

\begin{tabular}{cc}
\hline Sample & Mean value of $\Delta H_{\text {diss }} / \mathrm{kJ} \mathrm{mol}^{-1}$ \\
\hline Mnt A & $-846.80 \pm 7.64^{\mathrm{b}}$ \\
B & $-844.03 \pm 1.45^{\mathrm{b}}$ \\
C & -859.94 \\
D & $-847.84 \pm 2.95^{\mathrm{b}}$ \\
E & $-842.04 \pm 20.2^{\mathrm{b}}$ \\
F & $-840.77 \pm 2.52^{\mathrm{b}}$ \\
G & -859.50 \\
H & $-848.02 \pm 6.14^{\mathrm{b}}$ \\
I & -860.21 \\
K & -866.77 \\
L & -854.33 \\
M & -858.14 \\
IIlite N & -863.52 \\
\hline a Standard uncertainties are $u(T)=0.01 \mathrm{~K}$ and $u(p)=3 \mathrm{kPa}$. \\
b The expanded uncertainties are calculated using a Student's $t$-distribution with a 95 percent- \\
confidence interval.
\end{tabular}

The opposite values of the enthalpies of dissolution are plotted in Fig. $6 \mathrm{a}$ in the 3-D space $\left(\mathbf{F}_{1}, \mathbf{F}_{2}\right.$, $\left.\Delta H_{\text {diss }}\right)$. The values were then modeled by a polynomial surface by using the least-square fit method. The polynomial function is expressed by $P\left(z_{1}, z_{2}\right)=852.124-6.029 z_{1}+41.159 z_{2}+1.938 z_{1}^{2}-4.027 z_{1} z_{2}+$ $45.824 z_{2}^{2}$, where $z_{1}$ and $z_{2}$ correspond to the coordinates of the $\mathrm{I} / \mathrm{S}$ samples in the $\left(\mathbf{F}_{1}, \mathbf{F}_{2}\right)$ plane.

The discrepancies between the measured and modeled values are lower than $1 \%$, which correspond to the relative uncertainties for the measured enthalpies of dissolution. The modeled values are then considered to correctly represent the measured enthalpies.

\subsubsection{Enthalpies of mixing at $298.15 \mathrm{~K}$}

The illite-smectite compositions may be expressed by a linear combination of the compositions of the three end-members $\mathrm{A}, \mathrm{F}$ and $\mathrm{N}$. The barycentric coordinates $\left(a_{A}, a_{F}, a_{N}\right)$ for all $\mathrm{I} / \mathrm{S}$ samples are given in Table 13. With respect to these end-members, the enthalpy of mixing for an interstratified $X$ from the Shinzan series is the enthalpy of the reaction of formation:

$a_{A}$ Mnt $A+a_{N}$ illite $N+a_{F}$ mixed layer $F \rightarrow$ mixed layer $X$

(Reaction 3) 
which practically represents the enthalpy of mixing of illite and smectite (montmorillonite) layers. The enthalpy of mixing is then obtained from the combination of the reactions of dissolution of the minerals and is expressed by the following (Eq. (7)):

$\Delta H_{m}($ mixed layer $X)=a_{A} \Delta H_{\text {diss }}(A)+a_{N} \Delta H_{\text {diss }}(N)+a_{F} \Delta H_{\text {diss }}(F)-\Delta H_{\text {diss }}($ mixed layer $X)+\Delta H_{\text {mix }, \text { sol }}$

where $\Delta H_{m i x, s o l}$ is the enthalpy of mixing of solutions resulting from the dissolution reactions of the minerals, which is neglected in the following calculations. The enthalpies of mixing are then calculated for all illitesmectite compositions from the modeled values of the enthalpies of dissolution (Table 13) and are plotted in the $\left(\mathbf{F}_{1}, \mathbf{F}_{2}, \Delta H_{m}\right)$ space (Fig. 6b).

Table 13. Enthalpies of mixing of the $\mathrm{I} / \mathrm{S}$ minerals from the Shinzan area, at $298.15 \mathrm{~K}$ and $101 \mathrm{kPa}^{\mathrm{a}}$, with respect to the three end-members Mnt A, illite $\mathrm{N}$ and interstratified F. $a_{A}, a_{N}$ and $a_{F}$ are the barycentric coordinates of the $\mathrm{I} / \mathrm{S}$ minerals that are associated with the corresponding end-members.

\begin{tabular}{ccccc}
\hline Samples & $a_{A}$ & $a_{N}$ & $a_{F}$ & $\Delta H_{m} / \mathrm{kJ} \mathrm{mol}^{-1 \mathrm{~b}}$ \\
\hline Mnt A & 1.00 & 0.00 & 0.00 & 0.00 \\
B & 0.85 & -0.06 & 0.20 & 0.20 \\
$\mathrm{C}$ & 0.68 & 0.02 & 0.30 & -0.99 \\
$\mathrm{D}$ & 0.66 & 0.21 & 0.13 & -2.64 \\
$\mathrm{E}$ & 0.53 & 0.29 & 0.18 & -3.18 \\
$\mathrm{~F}$ & 0.00 & 0.00 & 1.00 & 0.00 \\
$\mathrm{G}$ & 0.97 & 0.58 & -0.55 & -2.98 \\
$\mathrm{H}$ & 0.50 & 0.52 & -0.02 & -3.70 \\
I & 0.40 & 0.47 & 0.12 & -3.62 \\
$\mathrm{~J}$ & 0.74 & 0.85 & -0.59 & -2.41 \\
$\mathrm{~K}$ & -0.25 & 0.48 & 0.77 & -1.47 \\
$\mathrm{~L}$ & -0.02 & 0.69 & 0.33 & -2.19 \\
M & 0.01 & 0.85 & 0.14 & -1.39 \\
Illite N & 0.00 & 1.00 & 0.00 & 0.00 \\
\hline a Standard uncertainties are $u(T)=0.01 \mathrm{~K}$ and $u(p)=3 \mathrm{kPa}$. \\
bxpanded uncertainties are obtained from error propagation calculation method using Eq. (7) and are \\
estimated at 5 kJ mol ${ }^{-1}$ with level of confidence 0.95 .
\end{tabular}



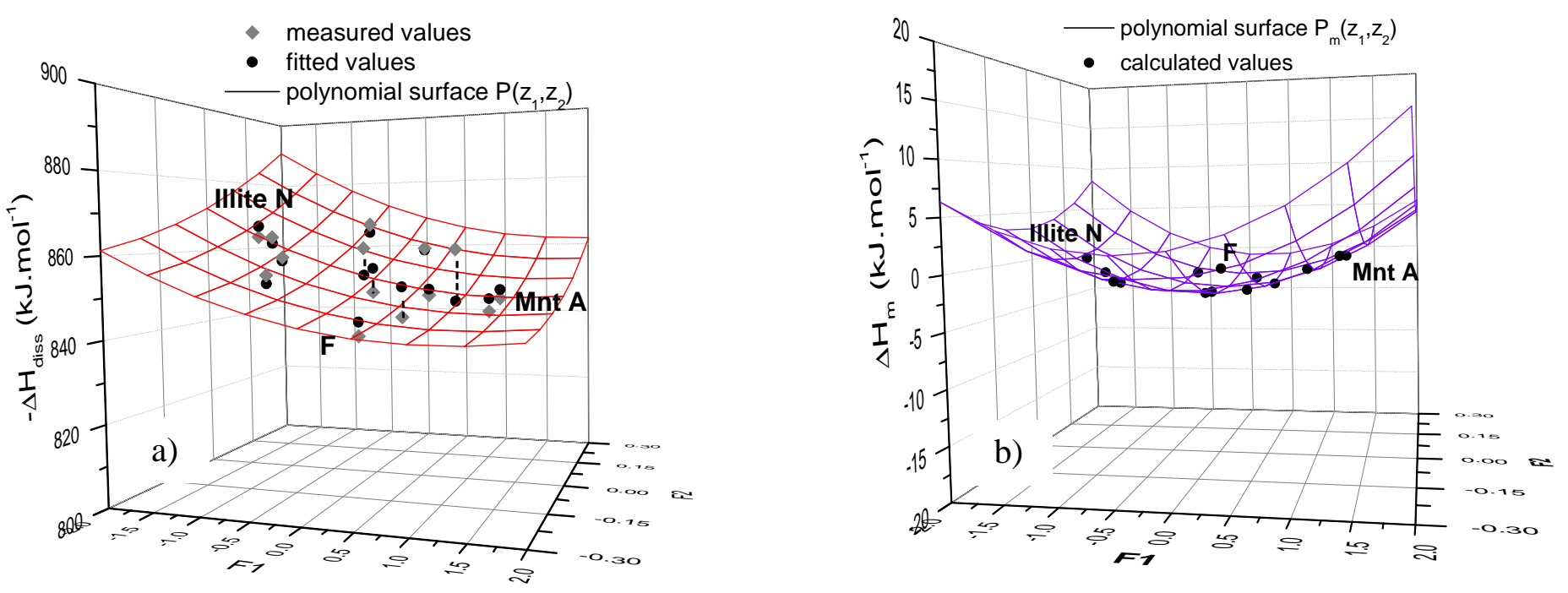

Fig. 6. 3-D plots of (a) the polynomial surface $P\left(z_{1}, z_{2}\right)$ obtained by fitting the experimental values of $-\Delta H_{\text {diss }}$ for the $I / S$ samples and (b) the enthalpies of mixing of the illite and smectite layers (per mol $\mathrm{O}_{10}(\mathrm{OH})_{2}$ ) for the $\mathrm{I} / \mathrm{S}$ minerals and the modeled polynomial surface $P_{m}\left(z_{1}, z_{2}\right)$. $F_{1}$ and $F_{2}$ are the main eigenvectors representing the main trends of chemical dispersion (see text).

The resulting enthalpies of mixing are slightly negative, with a minimum value of approximately $-3.7 \mathrm{~kJ}$ $\mathrm{mol}^{-1}$ for the $\mathrm{H}$ and I samples. According to XRD modeling (Inoue and Utada [7]), these latter samples are first-order R1 types and should contain approximately 30-35\% smectite layers. A model predicting $\Delta H_{m}$ was proposed by Blanc et al. [24] and resulted in $\Delta H_{m}=-3.6 \mathrm{~kJ} \mathrm{~mol}^{-1}$ for illite/smectite that displayed such composition and ordering types.

\section{Discussion: comparison with estimates and stability domains}

The standard thermodynamic properties of the illite-smectite ISCz-1 obtained experimentally are compared with the estimated values calculated from the model of Blanc et al. [1] that includes a consistent set of models for predicting the standard thermodynamic properties $\left(H, S, C_{p}, V\right)$ of phyllosilicates. First, the model from Blanc et al. [1] is applied merely by considering the whole structural formula of the illite-smectite. 
The simplified structural formula $\left(\mathrm{Ca}_{0.092} \mathrm{~K}_{0.439}\right)\left(\mathrm{Si}_{3.562} \mathrm{Al}_{0.438}\right)\left(\mathrm{Al}_{1.732} \mathrm{Mg}_{0.255} \mathrm{Fe}^{3+}{ }_{0.029} \mathrm{Fe}^{2+}{ }_{0.011}\right) \mathrm{O}_{10}(\mathrm{OH})_{2}$ is considered in order to ease the predictive calculations. The results are given in Table 14 . In addition, a second approach is conducted that separately predicts the thermodynamic parameters of the illite and smectite components and combines them according to the required composition of illite-smectite. This approach aims to differentiate the chemistry of the illite and smectite layers in the interstratified, consistently with the structure of the illite-smectite mineral.

The method for calculating the chemical compositions of illite and smectite end-members relies on the work of Meunier and Velde [2], which is based on the graphical representation of the $\mathrm{M}^{+}-4 \mathrm{Si}-\mathrm{R}^{2+}$ ternary system for natural sample compositions. Plotting ISCz-1 coordinates in such a diagram (Fig. 7) reveals that illite-smectite ISCz-1 can be considered as a binary solid solution with a high-charge illite end-member $\left(0.87 / \mathrm{O}_{10}(\mathrm{OH})_{2}\right)$, namely, IllitePP, and a low-charge montmorillonite end-member $(0.21)$, namely, MontmorillonitePP. Their coordinates in the $\mathrm{M}^{+}-4 \mathrm{Si}-\mathrm{R}^{2+}$ diagram provide some chemical constraints but these are not sufficient to determine their detailed compositions, i.e. interlayer cations $(\mathrm{K}, \mathrm{Ca})$ and octahedral cations ( $\mathrm{Al}, \mathrm{Mg}, \mathrm{Fe}^{2+}, \mathrm{Fe}^{3+}$ ) occupancies. A complementary approach was then developed, assuming ideal mixing between elements in the illite and smectite structural sites and based on the least-square fit method to adjust the compositions, by constraining the ratios between the elements in the I/S structural sites given from the structural formula of ISCz-1 mineral. The compositions of the end-members were determined considering $70 \%$ illite and $30 \%$ smectite, which is consistent with the proportions obtained from the XRD analyses. Finally, the thermodynamic properties of the illite and smectite end-members are calculated by using the model from Blanc et al. [1] for each end-member and then considering a linear combination of both. The dataset is completed by considering the mixing enthalpy measured for the I/S sample with $70 \%$ illite layers (sample I, Table 5) at $-3.6 \mathrm{~kJ} \mathrm{~mol}^{-1}$.

Regarding the results (reported in Table 14), the prediction obtained by considering the mixture of illite and smectite components falls closest to the experimental values, except for those of heat capacity and volume. For these latter properties, both estimate methods provide similar results and, on the whole, the method based on a mixture of layers slightly improves the accuracy of the predictions for the properties of the illite-smectite ISCz-1 mineral. 


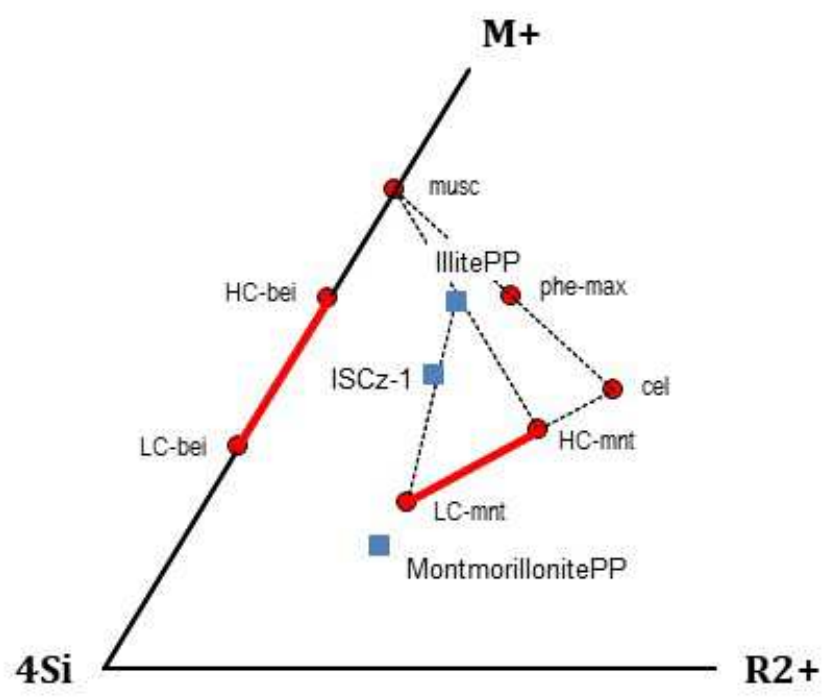

Fig. 7. Composition of clay minerals in the $\mathrm{M}^{+}-4 \mathrm{Si}-\mathrm{R}^{2+}$ system $\left(\mathrm{M}^{+}=\right.$layer charge of ideal mica, $4 \mathrm{Si}=\mathrm{Si}$ content of the tetrahedral sheet, and $\mathrm{R}^{2+}=$ amount of bivalent cations in the octahedral position). Musc $=$ Muscovite, phe-max $=$ Phengite, cel = celadonite, IllitePP = illite end-member (layer charge 0.87), HC-mnt = high-charge montmorillonite, LC$\mathrm{mnt}=$ low-charge montmorillonite, and beid $=$ beidellite. IllitePP and MontmorillonitePP are the predicted compositions of the illite and smectite components in the mixed-layer ISCz-1, respectively.

Table 14. Estimated thermodynamic properties of ISCz-1 at $298.15 \mathrm{~K}$ and $101.325 \mathrm{kPa}$ according to the model from [1]. Data are compared to the experimental values obtained for the simplified structural formula that was given in Table 11. $\Xi_{\text {exp }}$ and $\Xi_{\text {pred }}$ refers to experimental and predicted thermodynamic properties $\left(G, H, S, C_{p}, V\right)$, respectively.

\begin{tabular}{|c|c|c|c|c|c|}
\hline Predicted & $\begin{array}{c}\Delta G_{f}^{0} \\
/ \mathrm{kJ} \mathrm{mol}^{-1}\end{array}$ & $\begin{array}{c}\Delta H_{f}^{0} \\
/ \mathrm{kJ} \mathrm{mol}^{-1}\end{array}$ & $\begin{array}{c}S^{0 \text { (tot) }} \\
/ \mathrm{J} \mathrm{K}^{-1} \mathrm{~mol}^{-1}\end{array}$ & $\begin{array}{c}C_{p, m}^{\circ}(298.15 \mathrm{~K}) \\
/ \mathrm{J} \mathrm{K}^{-1} \mathrm{~mol}^{-1}\end{array}$ & $\begin{array}{c}V^{\mathrm{o}} \\
/ \mathrm{cm}^{3} \mathrm{~mol}^{-1}\end{array}$ \\
\hline Mean composition & -5412.63 & -5779.31 & 301.78 & 317.63 & 137.94 \\
\hline$\Xi_{\text {exp }}-\Xi_{\text {pred }}$ & -5.99 & -7.91 & -6.41 & -11.58 & -0.81 \\
\hline$\left(\Xi_{\text {exp }}-\Xi_{\text {pred }}\right) /\left|\Xi_{\text {exp }}\right|^{*} 100$ & -0.11 & -0.13 & -2.17 & -3.78 & -0.59 \\
\hline Mix illite/smectite layers ${ }^{a}$ & -5415.19 & -5785.52 & 290.03 & 317.79 & 138.00 \\
\hline Mixing terms & -3.6 & -3.6 & & & \\
\hline Final estimate & -5418.89 & -5789.22 & 290.03 & 317.79 & 138.00 \\
\hline$\Xi_{\text {exp }}-\Xi_{\text {pred }}$ & 0.27 & 2.00 & 5.33 & -11.74 & -0.87 \\
\hline$\left(\Xi_{\text {exp }}-\Xi_{\text {pred }}\right) /\left|\Xi_{\text {exp }}\right|^{*} 100$ & 0.00 & 0.03 & 1.80 & -3.84 & -0.63 \\
\hline
\end{tabular}


As stated by Blanc et al. [24], the mixing of layers introduces an additional entropy term, which is not directly measurable by calorimetry. The authors proposed a prediction model based on nearest neighbor interaction up to the fourth neighbor. In a simpler approach, we can first assume that the mixing entropy term is estimated for an ideal solid solution between illite and smectite end-members. In the case of the ISCz-1 sample with $70 \%$ illite, $\Delta S_{m}=5.38 \mathrm{~J} \mathrm{~K}^{-1} \mathrm{~mol}^{-1}$.

In Fig. 8, the stability fields for the ISCz-1, Illite and Montmorillonite end-members are drawn at $25^{\circ} \mathrm{C}$ by considering two different sets of thermodynamic parameters for ISCz-1:

- a set including $\Delta H_{m}$ for the ISCz-1 properties of formation (Fig. 8a), and

- a set excluding $\Delta H_{m}$ for the ISCz-1 properties of formation (Fig. 8b).

Comparing Fig. $8 \mathrm{a}$ and $\mathrm{b}$ highlights the importance of mixing terms. Indeed, the ISCz-1 stability field just disappears when the mixing terms are not integrated to the thermodynamic function, whereas it lies as expected between the illite and montmorillonite end-members when the mixing terms are added to the ISCz1 formation properties. Overall, in the calculation process followed here to predict the thermodynamic properties of illite/smectite, we consider a mixture of layers with the composition of the montmorillonite component ranging between high- and low-charge montmorillonite, which is consistent with Meunier and Velde [2]. As seen from Fig. 8, a simple mixture is not sufficient, and additional mixing terms are necessary to result in significant stability, ranging as expected between illite and montmorillonite end-members. 

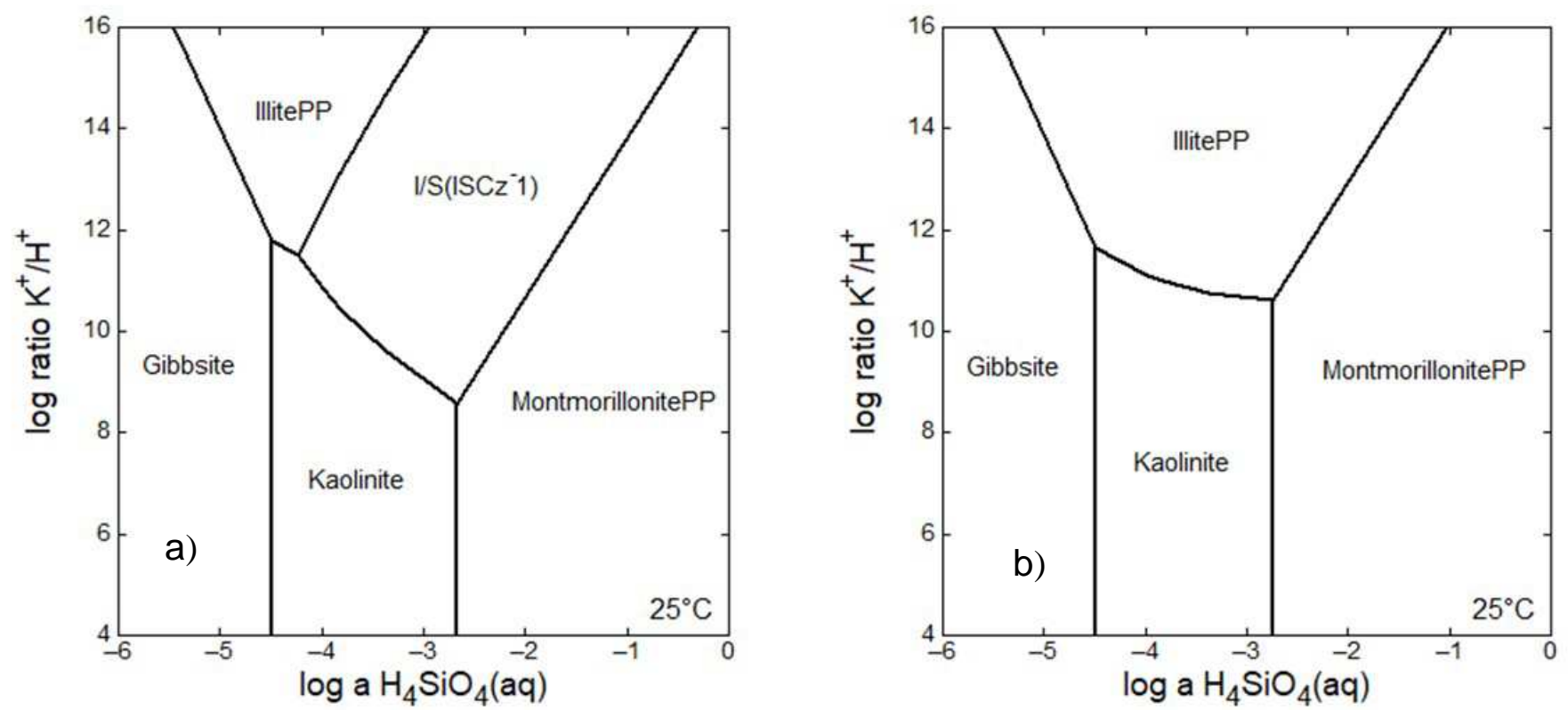

Fig. 8. Stability fields for the I/S ISCz-1 mineral at $298.15 \mathrm{~K}$ and ambient pressure of $101.325 \mathrm{kPa}$ : a) including enthalpy of mixing and b) without enthalpy of mixing.

\section{Summary and conclusions}

In early diagenesis and underground storage studies, the transformation of smectite into illite has long been recognized to involve the formation of interstratified illite/smectite as an intermediate product $([2,55])$. However, the lack of thermodynamic properties has prevented it from being implemented into geochemical calculations. This study presents the first direct calorimetric measurements of such properties.

These measurements were conducted using a purified, Ca-saturated ISCz-1 sample from Slovakia, which was provided by the Source Clays Repository of the Clay Minerals Society. $\Delta H^{\circ}{ }_{f}$ was obtained from acid solution calorimetry experiments, and $S^{\circ}$ and $C_{p, m}^{\circ}$ were measured by the PPMS and DSC techniques. In addition, a specific mixing enthalpy was measured by acid solution calorimetry, considering samples from the Shinzan hydrothermal series [7]. For the entire set of measured thermodynamic properties, the comparison with a previously published estimation method (Blanc et al. [1]) was favorable, provided that the estimate is calculated by distinguishing between the respective contributions of the illite and smectite layers. The respective compositions of the latter are derived from the compositional relations established by Meunier and Velde [2]. 
Among the concluding points, comparing the different estimating methods shows that the energetic terms for layer mixing are necessary for the mineral stability, even though their magnitudes are small with respect to the formation terms and may even fall within the uncertainties obtained for the formation terms. This implies that further improvements and advances could be made by considering weak energy terms such as hydration or exchange reaction contributions [56].

\section{Acknowledgements}

Financial support from the French Radioactive Waste Management Agency (ANDRA), from the French Geological Survey (BRGM) and from the French National Council for Scientific Research (CNRS) is gratefully acknowledged. The authors thank Professor A. Inoue, Chiba University, for supplying the illitesmectite samples from the Shinzan Area. The anonymous reviewer and Pr. Padua are also gratefully acknowledged for their useful comments for improving the manuscript. 


\section{Appendix A. Heat capacity raw data measured on the (Ca-saturated) illite-smectite ISCz-1 sample}

Table A-1. Heat capacities at constant pressure ${ }^{a}$ of the illite-smectite ISCz-1 sample, at dehydrated state, between $2 \mathrm{~K}$ and $520 \mathrm{~K}$. Series 1 and 2: PPMS on sample 1 (4.156 mg); Series 3 and 4: PPMS on sample 2 (14.926 mg); Series 5: DSC (140.03 mg).

\begin{tabular}{|c|c|c|c|c|c|}
\hline$T / \mathrm{K}^{\mathrm{b}}$ & $\begin{array}{c}C_{p}{ }^{\mathrm{C}} \\
/ \mathrm{J} \mathrm{K} \mathrm{K}^{-1} \mathrm{~g}^{-1}\end{array}$ & $T / K^{b}$ & $\begin{array}{c}C_{p}{ }^{\mathrm{C}} \\
/ \mathrm{J} \mathrm{K}^{-1} \mathrm{~g}^{-1}\end{array}$ & $T / \mathrm{K}^{\mathrm{b}}$ & $\begin{array}{c}C_{p}{ }^{\mathrm{C}} \\
/ \mathrm{JK}^{-1} \mathrm{~g}^{-1}\end{array}$ \\
\hline Series 1 & & Series 1 & & Series 2 & \\
\hline 50.62 & 0.0835 & 12.40 & 0.0029 & 51.98 & 0.0899 \\
\hline 49.00 & 0.0786 & 11.99 & 0.0027 & 53.47 & 0.0930 \\
\hline 47.37 & 0.0737 & 11.60 & 0.0025 & 55.00 & 0.0979 \\
\hline 45.81 & 0.0692 & 11.21 & 0.0022 & 56.52 & 0.1029 \\
\hline 44.31 & 0.0649 & 10.84 & 0.0021 & 58.04 & 0.1079 \\
\hline 42.85 & 0.0608 & 10.49 & 0.0019 & 59.57 & 0.1133 \\
\hline 41.51 & 0.0571 & 10.14 & 0.0018 & 61.07 & 0.1183 \\
\hline 40.14 & 0.0533 & 9.81 & 0.0016 & 62.59 & 0.1234 \\
\hline 38.82 & 0.0498 & 9.49 & 0.0015 & 64.10 & 0.1284 \\
\hline 37.52 & 0.0464 & 9.18 & 0.0014 & 65.61 & 0.1334 \\
\hline 36.27 & 0.0433 & 8.88 & 0.0013 & 67.12 & 0.1385 \\
\hline 35.07 & 0.0402 & 8.59 & 0.0012 & 68.63 & 0.1437 \\
\hline 33.91 & 0.0373 & 8.31 & 0.0011 & 70.14 & 0.1490 \\
\hline 32.80 & 0.0346 & 8.03 & 0.0011 & 71.65 & 0.1533 \\
\hline 31.71 & 0.0320 & 7.76 & 0.0010 & 73.15 & 0.1585 \\
\hline 30.66 & 0.0296 & 7.51 & 0.0009 & 74.66 & 0.1639 \\
\hline 29.62 & 0.0273 & 7.26 & 0.0009 & 76.18 & 0.1692 \\
\hline 28.64 & 0.0252 & 7.02 & 0.0008 & 77.69 & 0.1746 \\
\hline 27.69 & 0.0232 & 6.78 & 0.0008 & 79.21 & 0.1801 \\
\hline 26.77 & 0.0214 & 6.56 & 0.0007 & 80.72 & 0.1856 \\
\hline 25.89 & 0.0196 & 6.35 & 0.0007 & 82.24 & 0.1910 \\
\hline 25.06 & 0.0180 & 6.14 & 0.0006 & & \\
\hline 24.24 & 0.0166 & 5.72 & 0.0006 & & \\
\hline 23.44 & 0.0152 & 4.86 & 0.0005 & & \\
\hline 22.67 & 0.0139 & 4.11 & 0.0004 & & \\
\hline 21.86 & 0.0127 & 3.96 & 0.0004 & & \\
\hline 21.19 & 0.0117 & 3.83 & 0.0004 & & \\
\hline 20.45 & 0.0107 & 3.70 & 0.0004 & & \\
\hline 19.83 & 0.0098 & 3.58 & 0.0004 & & \\
\hline 19.17 & 0.0090 & 3.46 & 0.0004 & & \\
\hline 18.54 & 0.0083 & 3.35 & 0.0004 & & \\
\hline 17.91 & 0.0076 & 3.24 & 0.0004 & & \\
\hline 17.33 & 0.0070 & 3.13 & 0.0004 & & \\
\hline 16.76 & 0.0064 & 3.03 & 0.0004 & & \\
\hline 16.21 & 0.0059 & 2.93 & 0.0004 & & \\
\hline 15.66 & 0.0054 & 2.84 & 0.0004 & & \\
\hline 15.15 & 0.0049 & 2.75 & 0.0004 & & \\
\hline 14.66 & 0.0045 & 2.66 & 0.0004 & & \\
\hline 14.16 & 0.0041 & 2.57 & 0.0004 & & \\
\hline 13.70 & 0.0038 & 2.49 & 0.0004 & & \\
\hline 13.25 & 0.0034 & 2.41 & 0.0004 & & \\
\hline 12.82 & 0.0032 & 2.33 & 0.0004 & & \\
\hline
\end{tabular}




\begin{tabular}{|c|c|c|c|c|c|}
\hline$T / K^{b}$ & $\begin{array}{c}C_{p}{ }^{\mathrm{C}} \\
/ \mathrm{JK}^{-1} \mathrm{~g}^{-1}\end{array}$ & $T / \mathrm{K}^{\mathrm{b}}$ & $\begin{array}{c}C_{p}{ }^{\mathrm{C}} \\
/ \mathrm{J} \mathrm{K}^{-1} \mathrm{~g}^{-1}\end{array}$ & $T / K^{b}$ & $\begin{array}{c}C_{p}{ }^{\mathrm{C}} \\
/ \mathrm{JK}^{-1} \mathrm{~g}^{-1}\end{array}$ \\
\hline Series 2 (continued) & & Series 2 (continued) & & Series 2 (continued) & \\
\hline 83.75 & 0.1966 & 175.31 & 0.5030 & 289.10 & 0.7514 \\
\hline 85.27 & 0.2018 & 177.30 & 0.5079 & 291.10 & 0.7537 \\
\hline 86.78 & 0.2070 & 179.29 & 0.5152 & 293.12 & 0.7570 \\
\hline 88.28 & 0.2125 & 181.30 & 0.5204 & 295.12 & 0.7594 \\
\hline 89.80 & 0.2179 & 183.31 & 0.5269 & 297.14 & 0.7623 \\
\hline 91.31 & 0.2232 & 185.31 & 0.5318 & 299.17 & 0.7628 \\
\hline 92.82 & 0.2286 & 187.30 & 0.5369 & 301.17 & 0.7628 \\
\hline 94.34 & 0.2342 & 189.29 & 0.5438 & 303.19 & 0.7668 \\
\hline 95.86 & 0.2406 & 191.29 & 0.5481 & 305.22 & 0.7678 \\
\hline 97.37 & 0.2461 & 193.29 & 0.5537 & 307.22 & 0.7710 \\
\hline 98.88 & 0.2515 & 195.30 & 0.5589 & 309.24 & 0.7719 \\
\hline 100.42 & 0.2571 & 197.29 & 0.5644 & 311.28 & 0.7804 \\
\hline 101.91 & 0.2628 & 199.29 & 0.5699 & 311.56 & 0.7796 \\
\hline 103.44 & 0.2681 & 201.27 & 0.5759 & 313.53 & 0.7790 \\
\hline 104.95 & 0.2736 & 203.28 & 0.5814 & 315.76 & 0.7841 \\
\hline 106.47 & 0.2790 & 205.28 & 0.5870 & 317.98 & 0.7940 \\
\hline 107.98 & 0.2845 & 207.27 & 0.5917 & 320.22 & 0.7908 \\
\hline 109.48 & 0.2897 & 209.26 & 0.5965 & 322.45 & 0.7999 \\
\hline 111.01 & 0.2952 & 211.26 & 0.6041 & 324.70 & 0.8043 \\
\hline 112.51 & 0.3005 & 213.25 & 0.6071 & 326.92 & 0.8055 \\
\hline 114.04 & 0.3060 & 215.25 & 0.6103 & 329.20 & 0.8060 \\
\hline 115.53 & 0.3113 & 217.24 & 0.6162 & 331.44 & 0.8086 \\
\hline 117.05 & 0.3166 & 219.26 & 0.6200 & & \\
\hline 118.57 & 0.3217 & 221.26 & 0.6247 & Series 3 & \\
\hline 120.08 & 0.3277 & 223.26 & 0.6313 & 51.39 & 0.0869 \\
\hline 121.59 & 0.3324 & 225.25 & 0.6324 & 49.77 & 0.0819 \\
\hline 123.09 & 0.3379 & 227.25 & 0.6378 & 48.18 & 0.0772 \\
\hline 124.60 & 0.3430 & 229.24 & 0.6430 & 46.62 & 0.0726 \\
\hline 126.11 & 0.3484 & 231.26 & 0.6475 & 45.11 & 0.0682 \\
\hline 127.62 & 0.3531 & 233.26 & 0.6531 & 43.65 & 0.0640 \\
\hline 129.15 & 0.3582 & 235.26 & 0.6560 & 42.26 & 0.0600 \\
\hline 130.65 & 0.3635 & 237.23 & 0.6624 & 40.89 & 0.0561 \\
\hline 132.17 & 0.3681 & 239.23 & 0.6648 & 39.56 & 0.0526 \\
\hline 133.69 & 0.3733 & 241.22 & 0.6693 & 38.29 & 0.0492 \\
\hline 135.22 & 0.3788 & 243.22 & 0.6725 & 37.08 & 0.0461 \\
\hline 136.74 & 0.3836 & 245.23 & 0.6786 & 35.88 & 0.0430 \\
\hline 138.25 & 0.3884 & 247.22 & 0.6861 & 34.74 & 0.0400 \\
\hline 139.77 & 0.3936 & 249.22 & 0.6881 & 33.62 & 0.0372 \\
\hline 141.28 & 0.3984 & 251.21 & 0.6939 & 32.54 & 0.0346 \\
\hline 142.81 & 0.4031 & 253.18 & 0.6969 & 31.50 & 0.0321 \\
\hline 144.32 & 0.4082 & 255.17 & 0.7014 & 30.51 & 0.0299 \\
\hline 145.84 & 0.4127 & 257.17 & 0.7050 & 29.55 & 0.0277 \\
\hline 147.34 & 0.4180 & 259.17 & 0.7094 & 28.60 & 0.0256 \\
\hline 148.85 & 0.4229 & 261.17 & 0.7102 & 27.69 & 0.0237 \\
\hline 150.35 & 0.4284 & 263.16 & 0.7157 & 26.81 & 0.0219 \\
\hline 151.88 & 0.4323 & 265.16 & 0.7193 & 25.96 & 0.0202 \\
\hline 153.38 & 0.4374 & 267.14 & 0.7227 & 25.14 & 0.0186 \\
\hline 155.44 & 0.4436 & 269.13 & 0.7251 & 24.34 & 0.0171 \\
\hline 157.34 & 0.4499 & 271.13 & 0.7289 & 23.58 & 0.0158 \\
\hline 159.33 & 0.4550 & 273.13 & 0.7331 & 22.85 & 0.0146 \\
\hline 161.32 & 0.4617 & 275.14 & 0.7330 & 22.16 & 0.0134 \\
\hline 163.34 & 0.4650 & 277.14 & 0.7373 & 21.48 & 0.0124 \\
\hline 165.33 & 0.4724 & 279.13 & 0.7445 & 20.82 & 0.0115 \\
\hline 167.33 & 0.4793 & 281.12 & 0.7455 & 20.18 & 0.0106 \\
\hline 169.31 & 0.4850 & 283.10 & 0.7458 & 19.57 & 0.0097 \\
\hline 171.30 & 0.4912 & 285.10 & 0.7514 & 18.96 & 0.0090 \\
\hline 173.32 & 0.4962 & 287.11 & 0.7489 & 18.38 & 0.0083 \\
\hline
\end{tabular}




\begin{tabular}{|c|c|c|c|c|c|}
\hline$T / \mathrm{K}^{\mathrm{b}}$ & $\begin{array}{c}C_{p}{ }^{\mathrm{C}} \\
/ \mathrm{J} \mathrm{K}^{-1} \mathrm{~g}^{-1}\end{array}$ & $T / \mathrm{K}^{\mathrm{b}}$ & $\begin{array}{c}C_{p}{ }^{\mathrm{C}} \\
/ \mathrm{JK}^{-1} \mathrm{~g}^{-1}\end{array}$ & $T / \mathrm{K}^{\mathrm{b}}$ & $\begin{array}{c}C_{p}{ }^{\mathrm{C}} \\
/ \mathrm{JK}^{-1} \mathrm{~g}^{-1}\end{array}$ \\
\hline Series 3 (continued) & & Series 4 (cont & & Series 4 (continued) & \\
\hline 17.81 & 0.0077 & 58.08 & 0.1090 & 142.72 & 0.4042 \\
\hline 17.29 & 0.0071 & 59.60 & 0.1142 & 144.22 & 0.4094 \\
\hline 16.77 & 0.0066 & 61.11 & 0.1193 & 145.73 & 0.4141 \\
\hline 16.26 & 0.0061 & 62.63 & 0.1244 & 147.23 & 0.4191 \\
\hline 15.78 & 0.0056 & 64.13 & 0.1294 & 148.74 & 0.4240 \\
\hline 15.32 & 0.0052 & 65.66 & 0.1346 & 150.25 & 0.4285 \\
\hline 14.86 & 0.0048 & 67.14 & 0.1396 & 151.76 & 0.4331 \\
\hline 14.44 & 0.0045 & 68.65 & 0.1448 & 153.26 & 0.4380 \\
\hline 14.03 & 0.0041 & 70.16 & 0.1501 & 155.35 & 0.4446 \\
\hline 13.63 & 0.0038 & 71.66 & 0.1554 & 157.20 & 0.4501 \\
\hline 13.24 & 0.0036 & 73.18 & 0.1602 & 159.18 & 0.4558 \\
\hline 12.88 & 0.0033 & 74.69 & 0.1655 & 161.17 & 0.4616 \\
\hline 12.53 & 0.0031 & 76.19 & 0.1709 & 163.16 & 0.4678 \\
\hline 12.19 & 0.0029 & 77.70 & 0.1764 & 165.13 & 0.4736 \\
\hline 11.87 & 0.0027 & 79.22 & 0.1819 & 167.12 & 0.4790 \\
\hline 11.55 & 0.0025 & 80.72 & 0.1872 & 169.10 & 0.4851 \\
\hline 11.26 & 0.0023 & 82.24 & 0.1928 & 171.11 & 0.4909 \\
\hline 10.97 & 0.0022 & 83.76 & 0.1983 & 173.09 & 0.4964 \\
\hline 10.69 & 0.0021 & 85.26 & 0.2037 & 175.07 & 0.5022 \\
\hline 10.42 & 0.0019 & 86.77 & 0.2090 & 177.06 & 0.5078 \\
\hline 10.16 & 0.0018 & 88.29 & 0.2143 & 179.05 & 0.5138 \\
\hline 9.91 & 0.0017 & 89.80 & 0.2195 & 181.06 & 0.5193 \\
\hline 9.66 & 0.0016 & 91.30 & 0.2251 & 183.05 & 0.5252 \\
\hline 9.42 & 0.0015 & 92.82 & 0.2305 & 185.02 & 0.5307 \\
\hline 9.21 & 0.0015 & 94.33 & 0.2364 & 187.02 & 0.5362 \\
\hline 9.00 & 0.0014 & 95.84 & 0.2420 & 189.01 & 0.5417 \\
\hline 8.78 & 0.0013 & 97.35 & 0.2475 & 191.01 & 0.5470 \\
\hline 8.59 & 0.0012 & 98.87 & 0.2531 & 193.00 & 0.5522 \\
\hline 8.40 & 0.0012 & 100.39 & 0.2585 & 195.00 & 0.5575 \\
\hline 8.22 & 0.0011 & 101.90 & 0.2641 & 196.98 & 0.5627 \\
\hline 8.05 & 0.0011 & 103.41 & 0.2694 & 198.98 & 0.5684 \\
\hline 6.45 & 0.0007 & 104.92 & 0.2749 & 201.00 & 0.5737 \\
\hline 4.16 & 0.0004 & 106.44 & 0.2804 & 203.01 & 0.5791 \\
\hline 4.02 & 0.0004 & 107.96 & 0.2857 & 205.02 & 0.5840 \\
\hline 3.89 & 0.0004 & 109.46 & 0.2912 & 206.99 & 0.5889 \\
\hline 3.77 & 0.0004 & 110.98 & 0.2965 & 209.01 & 0.5935 \\
\hline 3.64 & 0.0004 & 112.49 & 0.3017 & 211.02 & 0.5985 \\
\hline 3.53 & 0.0003 & 114.00 & 0.3071 & 213.04 & 0.6034 \\
\hline 3.41 & 0.0003 & 115.50 & 0.3123 & 215.05 & 0.6075 \\
\hline 3.30 & 0.0003 & 117.01 & 0.3177 & 217.05 & 0.6118 \\
\hline 3.19 & 0.0003 & 118.53 & 0.3230 & 219.06 & 0.6173 \\
\hline 3.08 & 0.0003 & 120.04 & 0.3286 & 221.05 & 0.6221 \\
\hline 2.98 & 0.0003 & 121.54 & 0.3337 & 223.06 & 0.6253 \\
\hline 2.88 & 0.0003 & 123.04 & 0.3388 & 225.07 & 0.6307 \\
\hline 2.79 & 0.0003 & 124.54 & 0.3441 & 227.11 & 0.6343 \\
\hline 2.69 & 0.0003 & 126.07 & 0.3492 & 229.13 & 0.6401 \\
\hline 2.60 & 0.0003 & 127.57 & 0.3543 & 231.14 & 0.6442 \\
\hline 2.51 & 0.0003 & 129.07 & 0.3593 & 233.12 & 0.6475 \\
\hline 2.43 & 0.0003 & 130.59 & 0.3642 & 235.11 & 0.6523 \\
\hline \multirow[t]{2}{*}{2.34} & 0.0003 & 132.10 & 0.3696 & 237.11 & 0.6559 \\
\hline & & 133.63 & 0.3749 & 239.11 & 0.6601 \\
\hline Series 4 & & 135.15 & 0.3798 & 241.12 & 0.6644 \\
\hline 51.98 & 0.0889 & 136.67 & 0.3845 & 243.12 & 0.6688 \\
\hline 53.52 & 0.0939 & 138.16 & 0.3897 & 245.12 & 0.6736 \\
\hline 55.04 & 0.0989 & 139.68 & 0.3944 & 247.09 & 0.6764 \\
\hline 56.57 & 0.1039 & 141.21 & 0.3995 & 249.08 & 0.6818 \\
\hline
\end{tabular}




\begin{tabular}{|c|c|c|c|c|c|}
\hline$T / K^{b}$ & $\begin{array}{c}C_{p}{ }^{\mathrm{C}} \\
/ \mathrm{J} \mathrm{K}^{-1} \mathrm{~g}^{-1}\end{array}$ & $T / \mathrm{K}^{\mathrm{b}}$ & $\begin{array}{c}C_{p}{ }^{\mathrm{C}} \\
/ \mathrm{J} \mathrm{K}^{-1} \mathrm{~g}^{-1}\end{array}$ & $T / \mathrm{K}^{\mathrm{b}}$ & $\begin{array}{c}C_{p}{ }^{\mathrm{C}} \\
/ \mathrm{J} \mathrm{K}^{-1} \mathrm{~g}^{-1}\end{array}$ \\
\hline Series 4 (continued) & & Series 5 (continued) & & Series 5 (continued) & \\
\hline 251.08 & 0.6852 & 329.92 & 0.8424 & 464.75 & 1.0501 \\
\hline 253.06 & 0.6891 & 332.42 & 0.8640 & 467.25 & 1.0536 \\
\hline 255.08 & 0.6925 & 334.91 & 0.8527 & 469.74 & 1.0590 \\
\hline 257.08 & 0.6957 & 337.41 & 0.8486 & 472.24 & 1.0600 \\
\hline 259.06 & 0.7002 & 339.90 & 0.8715 & 474.74 & 1.0614 \\
\hline 261.06 & 0.7032 & 342.40 & 0.8628 & 477.24 & 1.0547 \\
\hline 263.03 & 0.7067 & 344.89 & 0.8768 & 479.73 & 1.0599 \\
\hline 265.02 & 0.7093 & 347.39 & 0.8736 & 482.23 & 1.0677 \\
\hline 267.01 & 0.7125 & 349.88 & 0.8767 & 484.73 & 1.0694 \\
\hline 269.01 & 0.7162 & 352.38 & 0.8967 & 487.23 & 1.0699 \\
\hline 271.03 & 0.7208 & 354.88 & 0.8895 & 489.72 & 1.0750 \\
\hline 273.02 & 0.7252 & 357.37 & 0.9008 & 492.22 & 1.0722 \\
\hline 275.02 & 0.7278 & 359.87 & 0.9099 & 494.72 & 1.0749 \\
\hline 277.01 & 0.7304 & 362.36 & 0.9055 & 497.21 & 1.0829 \\
\hline 278.98 & 0.7348 & 364.86 & 0.9235 & 499.71 & 1.0825 \\
\hline 280.98 & 0.7357 & 367.35 & 0.9182 & 502.21 & 1.0850 \\
\hline 282.97 & 0.7397 & 369.85 & 0.9184 & 504.70 & 1.0887 \\
\hline 284.97 & 0.7424 & 372.34 & 0.9369 & 507.20 & 1.0883 \\
\hline 286.99 & 0.7448 & 374.84 & 0.9295 & 509.70 & 1.0952 \\
\hline 289.00 & 0.7481 & 377.34 & 0.9370 & 512.19 & 1.0930 \\
\hline 291.01 & 0.7480 & 379.84 & 0.9469 & 514.69 & 1.0969 \\
\hline 293.01 & 0.7516 & 382.33 & 0.9412 & 517.19 & 1.0994 \\
\hline 294.99 & 0.7539 & 384.83 & 0.9531 & 519.68 & 1.1000 \\
\hline 297.00 & 0.7565 & 387.33 & 0.9510 & 522.18 & 1.1016 \\
\hline 299.02 & 0.7591 & 389.82 & 0.9527 & & \\
\hline 301.06 & 0.7622 & 392.32 & 0.9653 & & \\
\hline 303.08 & 0.7642 & 394.82 & 0.9614 & & \\
\hline 305.12 & 0.7657 & 397.31 & 0.9711 & & \\
\hline 307.15 & 0.7690 & 399.81 & 0.9760 & & \\
\hline 309.16 & 0.7704 & 402.31 & 0.9720 & & \\
\hline 311.17 & 0.7740 & 404.81 & 0.9834 & & \\
\hline 311.18 & 0.7732 & 407.30 & 0.9806 & & \\
\hline 313.38 & 0.7767 & 409.80 & 0.9850 & & \\
\hline 315.63 & 0.7787 & 412.30 & 0.9956 & & \\
\hline 317.84 & 0.7817 & 414.80 & 0.9918 & & \\
\hline 320.09 & 0.7844 & 417.30 & 0.9996 & & \\
\hline 322.32 & 0.7856 & 419.79 & 0.9998 & & \\
\hline 324.55 & 0.7891 & 422.29 & 0.9990 & & \\
\hline 326.79 & 0.7904 & 424.79 & 1.0110 & & \\
\hline 329.04 & 0.7919 & 427.29 & 1.0052 & & \\
\hline 331.26 & 0.7938 & 429.78 & 1.0101 & & \\
\hline & & 432.28 & 1.0183 & & \\
\hline Series 5 & & 434.78 & 1.0161 & & \\
\hline 302.47 & 0.8160 & 437.28 & 1.0231 & & \\
\hline 304.97 & 0.8144 & 439.77 & 1.0279 & & \\
\hline 307.47 & 0.8311 & 442.27 & 1.0215 & & \\
\hline 309.96 & 0.8135 & 444.77 & 1.0418 & & \\
\hline 312.46 & 0.8159 & 447.27 & 1.0357 & & \\
\hline 314.95 & 0.8274 & 449.77 & 1.0397 & & \\
\hline 317.45 & 0.8220 & 452.26 & 1.0386 & & \\
\hline 319.94 & 0.8405 & 454.76 & 1.0425 & & \\
\hline 322.44 & 0.8276 & 457.26 & 1.0496 & & \\
\hline 324.93 & 0.8346 & 459.75 & 1.0502 & & \\
\hline 327.43 & 0.8527 & 462.25 & 1.0509 & & \\
\hline
\end{tabular}

\footnotetext{
a PPMS measurements are performed at pressure $p=12 \mathrm{mPa}$ with standard uncertainty $u(p)=1 \mathrm{mPa}$, and DSC measurements at $p=$ $101 \mathrm{kPa}$ with $u(p)=2 \mathrm{kPa}$. Standard uncertainty corresponds to one standard deviation of the mean.

${ }^{\mathrm{b}}$ The standard uncertainty in temperature is $u(T)=10 \mathrm{mK}$ for PPMS measurements (series 1 to series 4$)$ and $u(T)=50 \mathrm{mK}$ for DSC measurements (series 5).
} 


\footnotetext{
${ }^{\mathrm{C}}$ The relative expanded uncertainties with level of confidence $0.95(K=2)$ are: $U_{r}\left(C_{p}\right)=0.05(2<T / \mathrm{K}<50), U_{r}\left(C_{p}\right)=0.02(50<T / \mathrm{K}<270)$, $U_{r}\left(C_{p}\right)=0.05(270<T / \mathrm{K}<300)$ and $U_{r}\left(C_{p}\right)=0.015(302<T / \mathrm{K}<520)$. Between 200 and $300 \mathrm{~K}$, the uncertainties associated with PPMS measurements are estimated by taking into account the discrepancy between measured values and fitted data using the polynomial function given in Section 3.1.1. (see text for explanation).
}

\section{Appendix B. References for heat capacity data of mineral impurities}

Table B-1. References for $C_{p}$ data of mineral impurities, used for the calculations of $C_{p}$ of the studied clay minerals.

\begin{tabular}{lll}
\hline Mineral & References for $C_{p}$ data & $T$ range \\
\hline Quartz & {$[57]$} & $50 \mathrm{~K} \mathrm{-520} \mathrm{K}$ \\
Kaolinite & {$[58]$} & $7 \mathrm{~K}-298 \mathrm{~K}$ \\
& {$[59]$} & $298.15 \mathrm{~K}-520 \mathrm{~K}$ \\
K-Feldspar (microcline) & {$[60]$} & $5 \mathrm{~K}-298 \mathrm{~K}$ \\
& {$[59]$} & $298.15 \mathrm{~K}-520 \mathrm{~K}$ \\
Goethite & {$[61]$} & $0.4 \mathrm{~K}-375 \mathrm{~K}$ \\
\hline
\end{tabular}

Appendix C. Standard enthalpies of formation of the secondary references (constituents) at $298.15 \mathrm{~K}$ and $101.325 \mathrm{kPa}$, used in the solution calorimetry experiments

Table C-1. Standard enthalpies of formation $\Delta H_{f}^{\circ}$ of the secondary references, at $298.15 \mathrm{~K}$ and $101.325 \mathrm{kPa}$.

\begin{tabular}{llll}
\hline \multicolumn{1}{c}{ Name } & Formula & \multicolumn{1}{c}{$\begin{array}{c}\Delta H_{f}^{\circ} \\
/ \mathrm{kJ} \mathrm{mol}^{-1}\end{array}$} & Reference \\
\hline Gibbsite & $\mathrm{Al}(\mathrm{OH})_{3}$ & $-1293.13( \pm 1.2)$ & {$[62]$} \\
Quartz & $\mathrm{SiO}_{2}$ & $-910.7( \pm 1.7)$ & {$[57]$} \\
Goethite & $\mathrm{FeOOH}$ & $-560.7( \pm 1.2)$ & {$[61]$} \\
Iron(II) oxide & $\mathrm{FeO}$ & $-272.04( \pm 2.1)$ & {$[54]$} \\
Calcium hydroxide & $\mathrm{Ca}(\mathrm{OH})_{2}$ & $-984.55( \pm 1.3)$ & {$[63]$} \\
Magnesium hydroxide & $\mathrm{Mg}(\mathrm{OH})_{2}$ & $-924.14( \pm 0.4)$ & {$[64]$} \\
Potassium nitrate & $\mathrm{KNO}_{3}$ & $-494.5( \pm 0.4)$ & {$[59]$} \\
Rutile & $\mathrm{TiO}_{2}$ & $-944.0( \pm 0.8)$ & {$[53]$} \\
\hline
\end{tabular}

All the thermodynamic data for the secondary references come from Thermoddem database (http://thermoddem.brgm.fr) except for $\mathrm{KNO}_{3}$, not available in the database.

\section{Appendix D. Supplementary data}

Supplementary data to this article can be found online at https://doi.org/10.1016/j.jct.2019.06.004. 


\section{References}

[1] Blanc, P., Vieillard P., Gailhanou, H., Gaboreau, S., Gaucher, E., Fialips, C.I., Madé, B., and Giffaut, E. (2015) A generalized model for predicting the thermodynamic properties of clay minerals. Amer. J. Sci. 315, 734-780.

[2] Meunier, A. and Velde, B. (1989) Solid solution in I/S mixed-layer minerals and illite. Amer. Miner. 74, 1106-1112.

[3] Perry, E. and Hower, J. (1970) Burial diagenesis in Gulf Coast pelitic sediments. Clays Clay Miner. 18, $165-177$.

[4] Hower, J., Eslinger, E.V., Hower, M , and Perry, E.A. (1976) Mechanism of burial metamorphism of argillaceous sediments: 1. Mineralogical and chemical evidence. Geol. Soc. Amer. Bull. 87, 725-737.

[5] Steiner, A. (1968) Clay minerals in hydrothermally altered rocks at Wairakei, New Zealand. Clays Clay Miner. 16, 193-213.

[6] McDowell, S.D. and Elders, W.A. (1980) Authigenic layer silicate minerals in borehole Elmoie I, Salton Sea geothermal field, California, U.S.A Contrib. Miner. Petr. 74, 293-310.

[7] Inoue, A. and Utada, M. (1983) Further investigations of a conversion series of dioctahedral mica/smectites in the Shinzan hydrothermal alteration area, northeast Japan. Clays Clay Miner. 31, 401-412. [8] Velde, B. and Vasseur, G. (1992) Estimation of the diagenetic smectite to illite transformation in timetemperature space. Amer. Miner. 77, 967-976.

[9] Powers, M.C. (1967). Fluid-release mechanisms in compacting marine mudrocks and their importance in oil exploration. A.A.P.G. Bull. 51, 1240-1254.

[10] Colten-Bradley, V.A.C. (1987). Role of pressure in smectite dehydration - Effects on geopressure and smectite-to-illite transformation. A.A.P.G. Bull. 71, 1414-1427.

[11] Osborne, M.J. and Swarbrick, R.E. (1997). Mechanisms for generating overpressure in sedimentary basins: A reevaluation. A.A.P.G. Bull. 81, 1023-1041. 
[12] Gaucher, E.C. and Blanc, P. (2006). Cement/clay interactions - A review: Experiments, natural analogues, and modelling. Waste Manage. 26, 776-788.

[13] Inoue, A., Lanson, B., Marques-Fernandes, M., Sakharov, B.A., Murakami, T., Meunier, A., and Beaufort, D. (2005). Illite-smectite mixed-layer minerals in hydrothermal alteration of volcanic rocks: I. Onedimensional XRD structure analysis and characterization of component layers. Clays Clay Miner. 53, 423439.

[14] Ylagan, R.F., Altaner, S.P., and Pozzuoli, A. (2000). Reaction mechanisms of smectite illitization associated with hydrothermal alteration from Ponza island, Italy. Clays Clay Miner. 48, 610-631.

[15] Murakami, T., Inoue, A., Lanson, B., Meunier, A., and Beaufort, D. (2005). Illite-smectite mixed-layer minerals in the hydrothermal alteration of volcanic rocks: II. One-dimensional HRTEM structure images and formation kinetics. Clays Clay Miner. 53, 440-451.

[16] Claret, F., Sakharov, B.A., Drits, V.A., Velde, B., Meunier, A., Griffault, L., and Lanson, B. (2004). Clay minerals in the Meuse-Heute Marne underground laboratory (France): Does clay diagenetic evolution depend on organic matter? Clays Clay Miner. 52, 515-532.

[17] McCarty, D.K., Sakharov, B.A., and Drits, V.A. (2008). Early clay diagenesis in Gulf Coast sediments: New insights from XRD profile modelling. Clays Clay Miner. 56, 359-379.

[18] Lanson, B., Sakharov, B.A., Claret, F., and Drits, V.A. (2009). Diagenetic smectite-to-illite transition in clay-rich sediments: A reappraisal of X-ray diffraction results using the multi-specimen method. Amer. J. Sci. 309, 476-516.

[19] Ferrage, E., Vidal, O., Mosser-Ruck, R., Cathelineau, M., and Cuadros, J. (2011). A reinvestigation of smectite illitization in experimental hydrothermal conditions: Results from X-ray diffraction and transmission electron microscopy. Amer. Miner. 96, 207-223.

[20] Yates, D.M. and Rosenberg, P.E. (1996). Formation and stability of end-member illite: I. Solution equilibration experiments at $100-250^{\circ} \mathrm{C}$ and $\mathrm{P}_{\mathrm{v}, \text { soln }}$. Geochim. Cosmochim. Acta 60, 1873-1883.

[21] Yates, D.M. and Rosenberg, P.E. (1997). Formation and stability of end-member illite: II. Solid equilibration experiments at $100-250^{\circ} \mathrm{C}$ and $\mathrm{P}_{\mathrm{v}, \text { soln }}$. Geochim. Cosmochim. Acta $61,3135-3144$. 
[22] Whitney, G. and Northrop, H.R. (1988). Experimental investigation of the smectite to illite reaction: Dual reaction mechanisms and oxygen-isotope systematics. Amer. Miner. 73, 77-90.

[23] Whitney, G. and Velde, B. (1993). Changes in particle morphology during illitization: an experimental study. Clays Clay Miner. 41, 209-218.

[24] Blanc, P., Bieber, A., Fritz, B., and Duplay, J. (1997) A short range interaction model applied to illite/smectite mixed-layer minerals. Phys. Chem. Miner. 24, 574-581.

[25] Gailhanou, H., Blanc, P., Rogez, J., Mikaelian, G., Kawaji, H., Olives, J., Amouric, M., Denoyel, R., Bourrelly, S., Montouillout, V., Vieillard, P., Fialips, C.I., Michau, N., and Gaucher, E.C. (2012). Thermodynamic properties of illite, smectite and beidellite by calorimetric methods: Enthalpies of formation, heat capacities, entropies and Gibbs free energies of formation. Geochim. Cosmochim. Acta 89, 279-301.

[26] Gailhanou, H., P. Blanc, Rogez, J., Mikaelian, G., Horiushi, K., Yamamura, Y., Saito, K., Kawaji, H., Warmont, F., Grenèche, J.M., Vieillard, P., Fialips, C. I., Giffaut, E., and Gaucher, E.C. (2013). Thermodynamic properties of saponite, nontronite, and vermiculite derived from calorimetric measurements. Amer. Miner. 98, 1834-1847.

[27] Giffaut, E., Grivé, M., Blanc, P., Vieillard, P., Colàs, E., Gailhanou, H., Gaboreau, S., Marty, N., Madé, B., and Duro, L. (2014). Andra thermodynamic database for performance assessment: ThermoChimie. App. Geochem. 49, 225-236.

[28] Blanc, P., Lassin, A., Piantone, P., Azaroual, M., Jacquemet, N., Fabbri, A., and Gaucher, E.C. (2012). Thermoddem: A geochemical database focused on low temperature water/rock interactions and waste materials. App. Geochem. 27, 2107-2116.

[29] Inoue, A., Kohyama, N., Kitagawa, R., and Watanabe, T. (1987). Chemical and morphological evidence for the conversion of smectite to illite. Clays Clay Miner. 35, 111-120.

[30] Chipera, S.J. and Bish, D.L. (2001). Baseline studies of the Clay Minerals Society Source Clays: powder X-ray diffraction analyses. Clays Clay Miner. 49, 398-409. 
[31] Amouric, M. and Olives, J. (1991). Illitization of smectite as seen by high-resolution transmission electron microscopy. Eur. J. Miner. 3, 831-835.

[32] Olives, J., Amouric, M., and Perbost, R. (2000) Mixed layering of illite-smectite: results from highresolution transmission electron microscopy and lattice-energy calculations. Clays Clay Miner. 48, 282-289.

[33] Gailhanou, H., van Miltenburg, J.C., Rogez, J., Olives, J., Amouric, M., Gaucher, E.C., and Blanc, P. (2007). Thermodynamic properties of anhydrous smectite MX-80, illite IMt-2 and mixed-layer illite-smectite ISCz-1 as determined by calorimetric methods. Part I: Heat capacities, heat contents and entropies. Geochim. Cosmochim. Acta 71, 5463-5473.

[34] Gaucher, E.C., Tournassat, C., Pearson, F.J., Blanc, P., Crouzet, C., Lerouge, C., and Altmann, S. (2009). A robust model for pore-water chemistry of clayrock. Geochim. Cosmochim. Acta 73, 6470-6487.

[35] Guyonnet, D., Touze-Foltz, N., Norotte, V., Pothier, C., Didier, G., Gailhanou, H., Blanc, P., and Warmont, F. (2009). Performance-based indicators for controlling geosynthetic clay liners in landfill applications. Geotext. Geomemb. 27, 321-331.

[36] Blanc, P., Legendre, O., and Gaucher, E.C. (2007). Estimate of clay minerals amounts from XRD pattern modelling: The Arquant model. Phys. Chem. Earth 23, 135-144.

[37] Cuadros, J. and Linares, J. (1996). Experimental kinetic study of the smectite-to-illite transformation. Geochim. Cosmochim. Acta 60, 439-453.

[38] Garg, N. and Skibsted, J. (2016). Pozzolanic reactivity of a calcined interstratified illite/smectite (70/30) clay. Cem. Concr. Res. 79, 101-111.

[39] Massiot, D., Fayon, F., Capron, M., King, I., Le Calvé, S., Alonso, B., Durand, J.O., Bujoli, B., Gan, Z., and Hoatson, G. (2002). Modelling one and two-dimensional solid-state NMR spectra. Magn. Reson. Chem. 40, 70-76.

[40] McCammon, C.A., Pring, A., Keppler, H., and Sharp, T. (1995). A study of bernalite, Fe(OH)3, using Mössbauer spectroscopy, optical spectroscopy and transmission electron microscopy. Phys. Chem. Miner. 22, 11-20. 
[41] Perbost, R., Olives, J., and Amouric, M. (2002). Thermodynamic stability of mixed-layer illite-smectite: Energetic calculations and microcalorimetric measurements, in: Hoteit, S., Tijani \& Shao (Eds.), Hydromechanical and Thermohydromechanical Behaviour of Deep Argillaceous Rock. Swets \& Zeitlinger, Lisse, 77-88.

[42] Dachs, E. and Bertoldi, C. (2005). Precision and accuracy of the heat-pulse calorimetric technique: lowtemperature heat capacities of milligram-sized synthetic mineral samples. Eur. J. Miner. 17, 251-261.

[43] Dachs, E. and Benisek, A. (2011). A sample-saving method for heat capacity measurements on powders using relaxation calorimetry. Cryogenics 51, 460-464.

[44] Stølen, S. and Grønvold, F. (1999). Critical assessment of the enthalpy of fusion of metals used as enthalpy standards at moderate to high temperatures. Thermochim. Acta 327, 1-32.

[45] Ditmars, D.A., Ishihara, S., Chang, S.S., and Bernstein, G.. (1982). Enthalpy and heat-capacity standard reference material: synthetic sapphire (a-Al2O3) from 10 to 2250 K. J. Res. N.B.S. 87, 159-163.

[46] Ganteaume, M., Coten, M., and Decressac, M. (1991). Un nouveau calorimètre en solution: le Calsol. Thermochim. Acta 178, 81-98.

[47] Kennedy, C.A., Stancescu, M., Marriott, R.A., and White, M.A. (2007). Recommendations for accurate heat capacity measurements using a Quantum Design physical property measurement system. Cryogenics 47, 107-112.

[48] Majzlan, J., Grevel, K. D., and Navrotsky A. (2003). Thermodynamics of iron oxides: Part II. Enthalpies of formation and relative stability of goethite $(\alpha-\mathrm{FeOOH})$, lepidocrocite $(\gamma-\mathrm{FeOOH})$, and maghemite $\left(\gamma-\mathrm{Fe}_{2} \mathrm{O}_{3}\right)$. Amer. Miner. 88, 855-859.

[49] Ulbrich, H.H. and Waldbaum, D.R. (1976). Structural and other contributions to the third-law entropies of silicates. Geochim. Cosmochim. Acta 40, 1-24.

[50] Townsend, M.G., Longworth, G., and Kodama, H. (1986). Magnetic interaction at low temperature in chlorite and its products of oxidation: a Mössbauer investigation. Can. Miner. 24, 105-115. 
[51] Gailhanou, H., Rogez, J., van Miltenburg, J.C., van Genderen, A.C.G., Grenèche, J.M., Gilles, C., Jalabert, D., Michau, N., Gaucher, E.C., and Blanc, P. (2009). Thermodynamic properties of chlorite CCa-2. Heat capacities, heat contents and entropies. Geochim. Cosmochim. Acta 73, 4738-4749.

[52] Ellison, S.L.R., Roesslein, M., and Williams, A. (2000). EURACHEM/CITAC Guide: quantifying uncertainty in analytical measurement, second ed., Laboratory of the Government Chemist, London.

[53] Cox, J.D., Wagman, D.D., and Medvedev, V.A. (1989). CODATA Key Values for Thermodynamics. Hemisphere Publishing Corp., New York.

[54] Chase, M.W.J. (1998). NIST-NAJAF thermochemical tables, fourth ed., National Institute of Standards and Technology, Washington D.C..

[55] Srodon, J. and Eberl, D. (1984). Illite, in: Micas, S.W. Bailey (Eds.), Reviews in Mineralogy 13, Mineralogical Society of America, Washington, D.C., pp. 495-544.

[56] Gailhanou, H., Vieillard, P., Blanc, P., Lassin, A., Denoyel, R., Bloch, E., De Weireld, G., Gaboreau, S., Fialips, C.I., Madé, B., and Giffaut, E. (2017). Methodology for determining the thermodynamic properties of smectite hydration. App. Geochem. 82, 146-163.

[57] Richet, P., Bottinga, Y., Denielou, L., Petitet, J.P., and Tequi, C. (1982). Thermodynamic properties of quartz, cristobalite and amorphous $\mathrm{SiO}_{2}$ : drop calorimetry measurements between 1000 and $1800 \mathrm{~K}$ and a review from 0 to 2000 K. Geochim. Cosmochim. Acta 46, 2639-2658.

[58] Robie, R.A. and Hemingway, B.S. (1991). Heat capacities of kaolinite from 7 to $380 \mathrm{~K}$ and of DMSOintercalated kaolinite from 20 to $310 \mathrm{~K}$. The entropy of kaolinite $\mathrm{Al}_{2} \mathrm{Si}_{2} \mathrm{O}_{5}(\mathrm{OH})_{4}$. Clays Clay Miner. 39, 362368.

[59] Robie, R.A. and Hemingway, B.S. (1995). Thermodynamic properties of minerals and related substances at $298.15 \mathrm{~K}$ and $1 \mathrm{Bar}\left(10^{5}\right.$ Pascals) pressure and at higher temperatures. U.S. Geol. Survey Bull. 2131, 1-461.

[60] Openshaw, R.E., Hemingway, B.S., Robie, R.A., Waldbaum, D.R., and Krupka K.M. (1976). The heat capacities at low temperatures and entropies at $298.15 \mathrm{~K}$ of low albite, analbite, microcline, and high sanidine. J. Res. U.S. Geol. Survey 4, 195-204. 
[61] Majzlan, J., Lang, B.E., Stevens, R., Navrotsky, A., Woodfield, B.F., and Boerio-Goates, J. (2003). Thermodynamics of Fe oxides: Part I. Entropy at standard temperature and pressure and heat capacity of goethite $(\alpha-\mathrm{FeOOH})$, lepidocrocite $(\gamma-\mathrm{FeOOH})$, and maghemite $\left(\gamma-\mathrm{Fe}_{2} \mathrm{O}_{3}\right)$. Amer. Miner. 88, 846-854.

[62] Pokrovskii, V.A. and Helgeson, H.C. (1995). Thermodynamic properties of aqueous species and the solubilities of minerals at high pressures and temperatures: The system $\mathrm{Al}_{2} \mathrm{O}_{3}-\mathrm{H}_{2} \mathrm{O}-\mathrm{NaCl}$. Amer. J. Sci. 295, $1255-1342$.

[63] Blanc, P., Bourbon, X., Lassin, A., and Gaucher, E.C. (2010). Chemical model for cement-based materials: Thermodynamic data assessment of amorphous and crystalline C-S-H phases. Cem. Concr. Res. 40, 851-866.

[64] Blanc, P., Bourbon, X., Lassin, A., and Gaucher, E.C. (2010). Chemical model for cement-based materials: Thermodynamic data assessment for phases other than C-S-H. Cem. Concr. Res. 40, 13601374. 